\title{
Therapeutic endoscopic ultrasound: European Society of Gastrointestinal Endoscopy (ESGE) Technical Review
}

Authors

Roy L. J. van Wanrooij ${ }^{1,{ }^{*}} \oplus^{\oplus}$, Michiel Bronswijk ${ }^{2,3,{ }^{*}} \oplus$, Rastislav Kunda ${ }^{\oplus}$, Simon M. Everett ${ }^{5}$, Sundeep Lakhtakia ${ }^{6}$, Mihai Rimbas $^{7} \oplus^{\circ}$, Tomas Hucl ${ }^{8}$, Abdenor Badaoui ${ }^{9}$, Ryan Law ${ }^{10}$, Paolo Giorgio Arcidiacono ${ }^{11}$, Alberto Larghi ${ }^{12}$, Marc Giovannini $^{13}$, Mouen A. Khashab ${ }^{14}$, Kenneth F. Binmoeller ${ }^{15}$, Marc Barthet ${ }^{16} \odot$, Manuel Pérez-Miranda ${ }^{17} \odot$, Jeanin E. van Hooft ${ }^{18} \oplus$, Schalk W. van der Merwe ${ }^{3}$

Institutions

1 Department of Gastroenterology and Hepatology, Amsterdam UMC, Vrije Universiteit Amsterdam, AGEM Institute, Amsterdam, The Netherlands

2 Department of Gastroenterology and Hepatology, Imelda General Hospital, Bonheiden, Belgium

3 Department of Gastroenterology and Hepatology, University Hospitals Leuven, Leuven, Belgium

4 Department of Surgery, Department of Gastroenterology and Hepatology, and Department of Advanced Interventional Endoscopy, Universitair Ziekenhuis Brussel, Vrije Universiteit Brussel, Brussels, Belgium

5 Department of Gastroenterology and Hepatology, Leeds Teaching Hospital NHS Trust, Leeds, UK

6 Department of Medical Gastroenterology, Asian Institute of Gastroenterology Hospitals, Gachibowli, Hyderabad, India

7 Gastroenterology Department, Colentina Clinical Hospital, Bucharest, Romania

8 Department of Gastroenterology and Hepatology, Institute for Clinical and Experimental Medicine, Prague, Czech Republic

9 Department of Gastroenterology and Hepatology, Université catholique de Louvain, CHU UCL Namur, Yvoir, Belgium

10 Department of Gastroenterology and Hepatology, Mayo Clinic, Rochester, Minnesota, USA

11 Pancreatobiliary Endoscopy and Endosonography Division, IRCCS San Raffaele Scientific Institute, Milan, Italy

12 Digestive Endoscopy Unit, Fondazione Policlinico Universitario A. Gemelli IRCCS, Università Cattolica del Sacro Cuore, and Center for Endoscopic Research Therapeutics and Training, Catholic University, Rome, Italy
13 Paoli-Calmettes Institute, Department of Gastrointestinal Disease, Marseille, France

14 Division of Gastroenterology and Hepatology, Johns Hopkins Hospital, Baltimore, Maryland, USA

15 Interventional Endoscopy Services, California Pacific Medical Center, San Francisco, California, USA

16 Department of Gastroenterology, Aix-Marseille Université, APHM, Hôpital Nord, Marseille, France

17 Gastroenterology Department, Hospital Universitario Rio Hortega, Valladolid, Spain

18 Department of Gastroenterology and Hepatology, Leiden University Medical Center, Leiden, The Netherlands

published online 3.2 .2022

Bibliography

Endoscopy 2022; 54: 310-332

DOI 10.1055/a-1738-6780

ISSN 0013-726X

(C) 2022. European Society of Gastrointestinal Endoscopy

All rights reserved.

This article is published by Thieme.

Georg Thieme Verlag KG, Rüdigerstraße 14,

70469 Stuttgart, Germany

Corresponding author

Schalk W. van der Merwe, MD PhD, Department of

Gastroenterology and Hepatology, University Hospital

Leuven, Belgium

Schalk.vandermerwe@uzleuven.be

\section{MAIN RECOMMENDATIONS}

1 ESGE recommends a prolonged course of a prophylactic broad-spectrum antibiotic in patients with ascites who are undergoing therapeutic endoscopic ultrasound (EUS) procedures.

Strong recommendation, low quality evidence. 
2 ESGE recommends placement of partially or fully covered self-expandable metal stents during EUS-guided hepaticogastrostomy for biliary drainage in malignant disease. Strong recommendation, moderate quality evidence.

3 ESGE recommends EUS-guided pancreatic duct (PD) drainage should only be performed in high volume expert centers, owing to the complexity of this technique and the high risk of adverse events.

Strong recommendation, low quality evidence.

4 ESGE recommends a stepwise approach to EUS-guided PD drainage in patients with favorable anatomy, starting with rendezvous-assisted endoscopic retrograde pancreatography (RV-ERP), followed by antegrade or transmural drainage only when RV-ERP fails or is not feasible. Strong recommendation, low quality evidence.
5 ESGE suggests performing transduodenal EUS-guided gallbladder drainage with a lumen-apposing metal stent (LAMS), rather than using the transgastric route, as this may reduce the risk of stent dysfunction.

Weak recommendation, low quality evidence.

6 ESGE recommends using saline instillation for small-bowel distension during EUS-guided gastroenterostomy.

Strong recommendation, low quality evidence.

7 ESGE recommends the use of saline instillation with a 19G needle and an electrocautery-enhanced LAMS for EUS-directed transgastric endoscopic retrograde cholangiopancreatography (EDGE) procedures.

Strong recommendation, low quality evidence.

8 ESGE recommends the use of either 15- or 20-mm LAMSs for EDGE, with a preference for 20-mm LAMSs when considering a same-session ERCP.

Strong recommendation, low quality evidence.

\section{SOURCE AND SCOPE}

This Technical review complements the recent European Society of Gastrointestinal Endoscopy (ESGE) Guideline on therapeutic endoscopic ultrasound. The aim of this Technical review is to discuss the technical considerations of therapeutic endoscopic ultrasound and the management of adverse events. The Grading of Recommendations Assessment, Development and Evaluation (GRADE) system was adopted to define the strength of recommendations and the quality of evidence.

\section{Introduction}

Endoscopic ultrasound (EUS) enables several therapeutic interventions in the pancreaticobiliary and gastrointestinal (GI) tract. A recent European Society of Gastrointestinal Endoscopy (ESGE) Guideline on therapeutic EUS provided an extensive overview of the indications and outcomes of these procedures [1]. EUS-guided management of fluid collections in acute necrotizing pancreatitis has been discussed in a previous ESGE guideline [2]. This review of the technical aspects of therapeutic EUS was commissioned by the ESGE to complement the guideline [1] focusing on procedural features and management of adverse events (AEs).

\section{Methods}

ESGE assigned this technical review and appointed a coordinating team (S.v.d.M., J.H., R.W., M.Br.). A team of experts across different domains of therapeutic EUS convened in May 2020. Two task force leaders (M.Ba. and M.P.M.) and their team members scrutinized the available literature for relevant articles per- taining to their fields of expertise. Topic-specific key questions were generated by each task force leader. Searches were performed using Medline (via Pubmed) and the Cochrane library up to June 2021. The level of evidence for each question was scored according to the Grading of Recommendations Assessment, Development and Evaluation (GRADE) system into high, moderate, low, or very low [3]. Recommendations were drafted and the strength of each was determined as strong or weak. Various web meetings were held to discuss and resolve issues, and formulate recommendations.

In October 2021, a final draft was sent to all group members for review. After all authors approved the final version, the manuscript was submitted to Endoscopy for publication. ESGE acknowledges that the field of therapeutic EUS is rapidly changing and that continued efforts will be required in the future to update and maintain these guidelines as more high quality published data are generated.

\section{General precautions and principles for therapeutic EUS}

\subsection{Key question 1: What are the general pre- and post-procedural precautions that should be taken when performing therapeutic EUS?}

\section{RECOMMENDATION}

ESGE recommends therapeutic EUS procedures should be performed by endoscopists with adequate training and experience, at centers where interventional radiology and hepatopancreaticobiliary surgical expertise are available.

Strong recommendation, low quality evidence. 


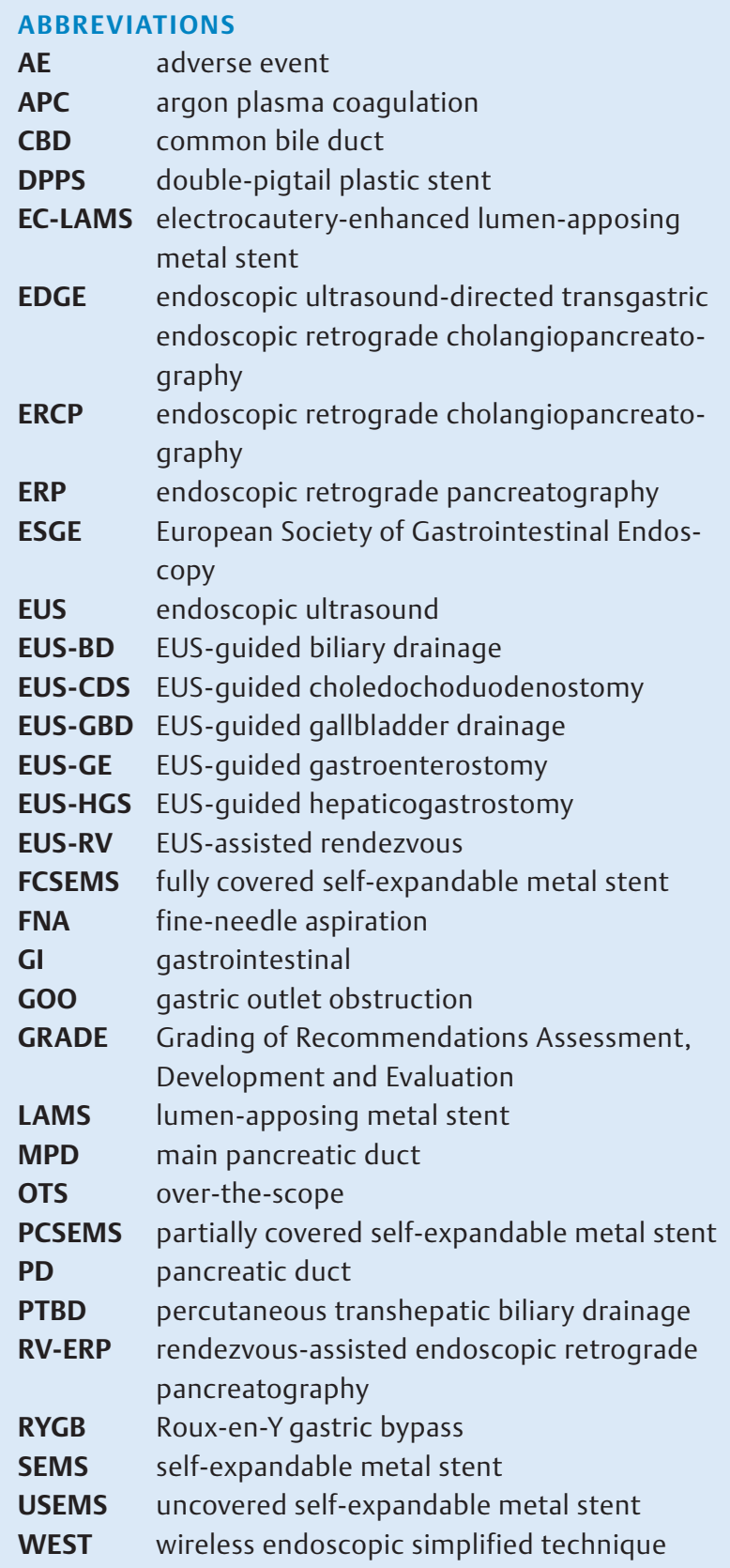

\subsubsection{General considerations}

Patients considered for therapeutic EUS procedures should be carefully selected based on criteria provided in the ESGE guideline [1]. In some settings, multidisciplinary discussions may be applicable before embarking on these procedures. Patients should be made aware of specific procedure-related risks and potential alternative therapeutic strategies when providing informed consent.

The endoscopist performing the procedure should have adequate experience in therapeutic EUS and endoscopic retrograde cholangiopancreatography (ERCP), as the level of the endoscopist's experience determines procedural outcome [49]. In addition, the availability of hepatopancreaticobiliary surgical and interventional radiological expertise is recommended in centers where therapeutic EUS procedures are performed, in case AEs occur $[10,11]$.

\subsubsection{Preprocedural considerations}

\section{RECOMMENDATIONS}

ESGE recommends temporary discontinuation of anticoagulant therapy before embarking on therapeutic EUS procedures.

Strong recommendation, low quality evidence.

ESGE recommends temporarily switching dual antiplatelet therapy to aspirin monotherapy, whenever possible, before embarking on therapeutic EUS procedures.

Strong recommendation, low quality evidence.

ESGE suggests prophylactic administration of an intravenous broad-spectrum antibiotic in all patients undergoing therapeutic EUS procedures.

Weak recommendation, low quality evidence.

ESGE recommends a prolonged course of a prophylactic broad-spectrum antibiotic in patients with ascites who are undergoing therapeutic EUS procedures.

Strong recommendation, low quality evidence.

According to the recent ESGE guideline on antiplatelet or anticoagulation therapy use in endoscopy, therapeutic EUS procedures are classified "high risk" [12]. In accordance with this guideline, before embarking on a therapeutic EUS procedure, anticoagulant therapy should be temporarily discontinued, while dual antiplatelet therapy should be converted to aspirin monotherapy where possible. However, small series have described the successful use of fully covered self-expandable metal stents (FCSEMSs) or lumen-apposing metal stents (LAMSs) in bile duct and gallbladder drainage procedures in patients on anticoagulant and/or antiplatelet therapy $[13,14]$. The inherent radial expansion forces of these stents will likely contribute to a reduced risk of periprocedural bleeding by providing a tamponade effect on the intraparietal blood vessels $[13,15]$. Even though these data are encouraging, more high quality evidence is needed before the current ESGE recommendations can be reconsidered.

Prophylactic administration of broad-spectrum antibiotics may prevent infectious AEs following a therapeutic EUS procedure. There are currently no data available that have reported prophylactic antibiotics to be beneficial in therapeutic EUS. Until more data become available, it is recommended that a single dose of intravenous antibiotics is administered when a transmural therapeutic procedure is performed, analogous to surgical and interventional radiology protocols $[16,17]$. Longer administration periods may be required in the presence of ascites, in immunocompromised patients, or in those where adequate biliary drainage was not achieved. 
A large volume of ascites may increase the difficulty of therapeutic EUS as it may prevent access to the target organ with a fine-needle aspiration (FNA) needle or stent catheter, and may lead to stent migration and cause bacterial peritonitis $[18,19]$. When a therapeutic EUS procedure is still deemed necessary, a preprocedural paracentesis may be helpful before embarking on such a procedure.

\subsubsection{Periprocedural considerations}

Adequate support to protect the patient's airway and prevent aspiration is regarded as indispensable during therapeutic EUS. Many centers perform therapeutic EUS exclusively in intubated and mechanically ventilated patients under general anesthesia, whilst conscious/deep sedation is used in other experienced centers without compromising safety outcomes. Procedures should ideally be performed in a fluoroscopy room, where imaging may be especially helpful in providing guidance if endoscopic salvage procedures are required.

\subsubsection{Post-procedural considerations}

The duration of post-procedural hospitalization for observation should be based on a patient's characteristics, such as medical co-morbidities, and procedural aspects, including a higher risk and/or greater difficulty of the procedure. Imaging studies (e. g. CT scan) should be performed when a post-procedural AE is suspected.

\subsection{Key question 2: What are the general technical principles in therapeutic EUS?}

\subsubsection{Which interventional therapeutic techniques are used?}

Therapeutic EUS uses various different approaches to obtain access to the target structure. The "rendezvous" technique (or "EUS-assisted" procedure) refers to the use of EUS to provide ductal access to facilitate subsequent ERCP, and is therefore considered an "indirect technique." "EUS-guided" interventions refer to procedures performed under EUS guidance and therefore considered "direct techniques."

Direct EUS-guided interventions typically involve transmural stent placement. These procedures can either be performed by a multistep approach, where access to the target organ is obtained using an FNA needle and guidewire that allows overthe-wire insertion of various tools and placement of a stent, or alternatively, an all-in-one approach using an electrocauteryenhanced lumen-apposing metal stent (EC-LAMS), which permits "free-hand" insertion of this device into the target structure without prior placement of a guidewire. The latter technique obviates the need for multiple accessory exchanges, thereby potentially reducing the risk of procedural failure and AEs. Some EUS-guided interventions may be further assisted by the use of additional accessories such as catheters (i.e. nasobiliary) or balloons.

When the target structures of interventional EUS are the pancreatic and biliary ducts, direct techniques may allow antegrade, as well as transmural, drainage. In addition to retrograde procedures by ERCP, antegrade procedures reinstate the normal flow direction by bridging a stenosis and/or papilla, whereas transmural drainage redirects flow away from the normal route by creating a new anastomosis.

\subsubsection{General technical principles in EUS-assisted and EUS-guided techniques}

\section{RECOMMENDATIONS}

ESGE suggests a fistulous tract be created using a 6-Fr cystotome or alternatively by mechanical dilation. Weak recommendation, low quality evidence.

ESGE recommends that endoscopists should undergo rigorous training in lumen-apposing metal stent placement and the management of adverse events before undertaking therapeutic EUS procedures using these devices. Strong recommendation, low quality evidence.

During EUS-assisted rendezvous (EUS-RV), access to the target structure is obtained using an EUS-FNA needle (most commonly a $19 \mathrm{G}$ needle as it accommodates guidewires up to 0.035 -inch diameter). Before the injection of contrast, adequate positioning of the needle tip inside the target lumen should be confirmed by EUS. When a bile duct is punctured, aspiration of bile may further confirm proper needle positioning. Correct needle placement is followed by contrast injection to depict the anatomy of the target structure (pancreatic or biliary duct, gallbladder, small intestine, or stomach). The needle is ideally rinsed with saline every time contrast is injected, to prevent subsequent difficulties with guidewire advancement due to the adhesive properties of the contrast medium. Because of its stiffness, some endoscopists favor the use of a 0.035 -inch guidewire of $450 \mathrm{~cm}$ in length with an $19 \mathrm{G}$ FNA needle. However, this may shear easily, hampering wire manipulation and leaving residual foreign material behind in the target when a beveled needle is being used. In order to overcome shearing, an atraumatic "access" needle may be used. Alternatively, a 19G FNA needle may be combined with a thinner 0.025 -inch monofilament guidewire that is less prone to shearing [20].

When the diameter of the target organ is limited, such as for biliary access, a thinner $22 \mathrm{G}$ needle may be preferred over a $19 \mathrm{G}$ needle, which can accommodate small 0.021 -inch or 0.018 -inch guidewires [21]. However, subsequent device advancement can be considerably more challenging when using small caliber guidewires. In addition, small caliber guidewires are not insulated against electrical current and are therefore not compatible with the concomitant use of cautery-based devices such as cystotomes.

Guidewire manipulation in EUS-guided biliary drainage (EUS-BD) is critical, especially in EUS-RV and antegrade transpapillary (or transanastomotic) stent placement, as successful passage of the stricture and/or papilla is required to complete the procedure. If the direction of the wire is undesirable, a wire with an angulated tip or a torque device may aid in steering it across a stricture. Recently, a steerable access needle has 
been developed, which facilitates guidewire advancement in the desired direction and appears to be especially useful in EUS-RV, where cystotomes or sphincterotomes are not commonly used [22, 23].

In EUS-RV, the wire is advanced via the pancreatic or biliary duct into the duodenum, after which the echoendoscope is removed and exchanged for a duodenoscope, while leaving the guidewire in place for subsequent ERCP. In EUS-guided procedures, successful guidewire placement is followed by the creation of a fistulous tract, which enables subsequent transmural or antegrade stent placement.

Fistula tract dilation can be achieved using mechanical or cautery devices. For mechanical dilation, a tapered dilating catheter or a hydrostatic balloon may be used [20,24]. Mechanical dilation limits damage to surrounding structures. These devices are however sometimes difficult to insert across the puncture tract, which may then compromise the stability of the endoscope.

Cautery devices enable the application of pure cutting current to overcome this problem. A coaxial cystotome is preferred over a needle-knife because the latter has been identified as a risk factor for AEs in EUS-BD [25]. More specifically, the 6-Fr cystotome is an ideal accessory that creates a tract that allows the introduction of various tools and stent-introducing catheters, without leading to clinically significant bile leakage or capnoperitoneum/pneumoperitoneum if the procedure should fail [26]. The 6-Fr cystotome is however not universally available and, in this specific context, mechanical dilation is preferred over the use of a 10-Fr cystotome, as such a large caliber device may lead to significantly more thermal injury to the surrounding structures, potentially resulting in leakage of Gl contents and free air if the procedure should fail.

The development of EC-LAMSs has enabled one-step direct access and drainage of the common bile duct and gallbladder; they are also used to create anastomoses in the GI tract. The development of EC-LAMSs has revolutionized the field of therapeutic EUS owing to their following unique characteristics. First, the all-in-one device obviates the need to use multiple tools, avoiding device exchanges that could potentially lead to procedural failure and AEs. Second, their dumbbell shape prevents migration and fuses the individual wall layers together, forming a mature anastomosis. Third, LAMSs are fully covered and leakage of bile or gastric acid intra-abdominally is rare. This characteristic also facilitates stent removal when indicated [27]. EC-LAMSs are available in various sizes in order to meet specific procedural needs ( $>$ Table $\mathbf{1}$ ).

Initially, EC-LAMSs were introduced over a guidewire, but this technique has fallen out of favor as the guidewire may actually push the target structure away from the GI wall, leading to stent maldeployment [28]. Therefore, EC-LAMSs are preferably introduced directly into the target structure using pure cutting current, referred to as the "free-hand technique." An endosonographic window where the target organ is within 10$20 \mathrm{~mm}$ from the GI wall (depending on the stent design), without intervening large blood vessels or ascites, should be sought. Placement of the LAMS is performed by applying pure cutting current (Autocut 100-150 W, effect 3-5) just before advancing the cautery tip to ensure rapid bridging of the GI layers into the target structure and to lessen coagulation artefacts that may obscure the view of the device. When the electrocautery tip is in position within the target structure, the distal flange of the LAMS can be deployed under endosonographic control. When adequately deployed, the distal flange is pulled towards the Gl wall until its shape changes from flat to oval, indicating adequate approximation of the layers to allow for safe release of the proximal flange inside the GI lumen. More control over the stent position can be achieved by the proximal flange of the LAMS being deployed inside the working channel of the echoendoscope and slowly expelled under endoscopic control [29].

- Table 1 The currently available electrocautery-enhanced lumen-apposing metals stents.

\begin{tabular}{|c|c|c|c|c|c|c|}
\hline \multirow[t]{2}{*}{ Stent } & \multirow[t]{2}{*}{ Manufacturer } & \multicolumn{3}{|c|}{ Stent measurements, mm } & \multicolumn{2}{|c|}{ Delivery system } \\
\hline & & $\begin{array}{l}\text { Internal } \\
\text { diameter }\end{array}$ & $\begin{array}{l}\text { Flange } \\
\text { diameter }\end{array}$ & $\begin{array}{l}\text { Saddle } \\
\text { length }\end{array}$ & Profile, Fr & $\begin{array}{l}\text { Usable } \\
\text { length, cm }\end{array}$ \\
\hline \multirow[t]{6}{*}{ Hot Axios } & \multirow{6}{*}{$\begin{array}{l}\text { Boston Scientific, Marlborough, } \\
\text { Massachusetts, USA }\end{array}$} & 6 & 14 & 8 & 9 & 138 \\
\hline & & 8 & 17 & 8 & 9 & 138 \\
\hline & & 10 & 21 & 10 & 10.8 & 138 \\
\hline & & 15 & 24 & 10 & 10.8 & 138 \\
\hline & & 15 & 24 & 15 & 10.8 & 138 \\
\hline & & 20 & 29 & 10 & 10.8 & 138 \\
\hline \multirow[t]{3}{*}{ Hot Spaxus } & \multirow{3}{*}{$\begin{array}{l}\text { Taewoong Medical, Gyeonggi-do, } \\
\text { South Korea }\end{array}$} & 8 & 23 & $20 / 7^{*}$ & 10 & 180 \\
\hline & & 10 & 25 & $20 / 7^{*}$ & 10 & 180 \\
\hline & & 16 & 31 & $20 / 7^{*}$ & 10 & 180 \\
\hline
\end{tabular}


After successful placement of LAMSs, adequate stent position should be confirmed by either endoscopic confirmation of recognizable fluid (e.g. bile, or blue-dyed liquid in the case of EUS-GE) being released from the stent, or contrast injection through the stent, which will fluoroscopically confirm correct placement within the target structure. It is of utmost importance to immediately recognize stent maldeployment during the procedure, so that adequate salvage measures may be undertaken as described in the sections below. Therefore, adequate training in LAMS placement and the management of AEs should be a prerequisite before performing therapeutic EUS procedures.

\subsubsection{When should a therapeutic EUS procedure be} aborted?

\section{RECOMMENDATION}

ESGE recommends discontinuation of the procedure when tumor infiltration, significant ascites, or large intervening blood vessels are identified at the desired puncture site of the gastrointestinal wall or target organ. Strong recommendation, low quality evidence.

Certain findings during the procedure may prevent successful completion and will require the endoscopist to abort. These include identifying infiltrating tumor or large blood vessels in the GI wall or target organ along the trajectory of the desired puncture site. Under these circumstances, the procedure should be aborted owing to an increased risk of stent maldeployment and bleeding [20]. The same risks apply, when the target structure is located at a distance of more than 15-20 $\mathrm{mm}$, if a significant volume of ascites is present, or if intervening bowel loops are detected.

In some instances, the procedure needs to be abandoned after an EUS needle, cystotome, or electrocautery device has already been used to puncture a structure. In such circumstances, mucosal closure may be considered and the patient should be observed for longer for any evidence of AEs. Diagnostic imaging should be performed immediately in such cases and interventional radiology or surgery may be warranted in rare instances.

\section{Biliary and pancreatic duct drainage}

EUS-guided drainage of the biliary system (EUS-BD) or the pancreatic ducts (EUS-guided PD drainage) may be required when conventional ERCP fails. How these procedures compare with percutaneous and surgical alternatives, and when they should be undertaken is discussed in greater detail in the ESGE guideline on therapeutic EUS [1].

\subsection{Key question 3: How should EUS-BD be performed?}

\subsubsection{EUS-assisted rendezvous}

Almost all EUS-RVs are accomplished with the linear echoendoscope positioned in the duodenal bulb $[30,31]$ ( Fig. 1a). The procedure is also possible by approaching the left intrahepatic bile ducts from the proximal stomach and advancing the wire across the papilla for subsequent ERCP, provided that the intrahepatic bile ducts are sufficiently dilated.

The common bile duct (CBD) or intrahepatic ducts are generally punctured with a 19G FNA needle, although, when only mildly dilated, a thinner $22 \mathrm{G}$ needle may be preferred [21]. After adequate needle positioning has been confirmed, a cholangiogram is performed. The guidewire should then be manipulated across the papilla into the duodenum where it is coiled. At this point, the echoendoscope is carefully removed leaving the guidewire behind. A duodenoscope is then introduced alongside the guidewire and advanced up to the level of the papilla. A sphincterotome can then be advanced directly adjacent to the guidewire where it protrudes from the papilla, which may allow CBD cannulation. Alternatively, the guidewire protruding from the papilla and coiled in the duodenum may be grasped using a forceps or snare and pulled through the working channel of the duodenoscope, over which a sphincterotome may then be advanced into the CBD. During this step, care should be taken to grasp an adequate length of the guidewire, in order to prevent wire fracture near its floppy tip.

\subsubsection{EUS-guided antegrade stenting}

For EUS-guided antegrade stenting, the echoendoscope is positioned in the stomach and directed so that the intrahepatic bile ducts of the left liver lobe can be visualized ( $\vee$ Fig. 1b), whilst at the same time avoiding a transesophageal puncture, which may carry a higher risk of AEs [32]. The intrahepatic bile ducts are punctured preferably at a depth of $2.5-3 \mathrm{~cm}$, so that the surrounding liver parenchyma will contain any potential bile leakage [33]. A cholangiogram will provide a "roadmap" that will aid in guidewire passage across the stricture and/or papilla. When the guidewire is safely coiled up within the small intestine or positioned deep into the intrahepatic bile ducts, a fistulous tract can be created using a cystotome or dilation balloon, which allows the introduction of the accessories that will aid in performing sphincteroplasty, stricture dilation, brush cytology, stone removal, and/or SEMS placement.

Adequate dilation of a distal stricture should be considered before placement of a transpapillary stent as the direction of the stent catheter away from the papilla can lead to loss of stiffness and ability to advance the stent catheter. When intraductal pressure is relieved from the biliary system by downstream stent placement, the risk of bile leakage from the puncture tract is negligible. Conversely, when stent placement across the obstruction fails, the risk of bile leakage is of concern and warrants salvage biliary drainage, either with EUS-guided hepaticogastrostomy (EUS-HGS) or percutaneous transhepatic biliary duct drainage (PTBD). 


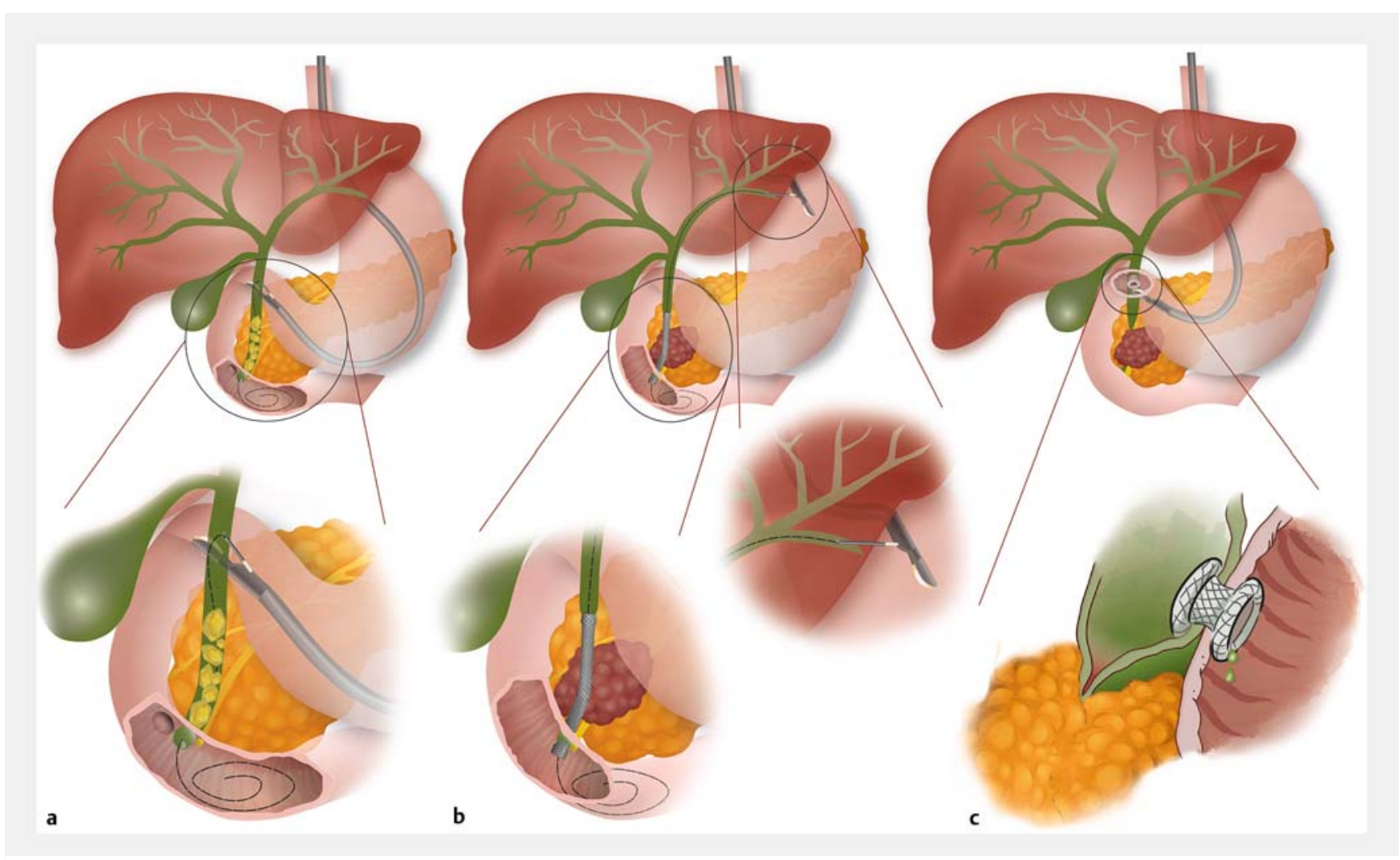

- Fig. 1a-c Illustrations of therapeutic endoscopic ultrasound (EUS) interventions of the pancreaticobiliary and gastrointestinal tract showing: a EUS-assisted rendezvous (biliary); b EUS-guided antegrade stenting; c EUS-guided choledochoduodenostomy. Source: Martha Meisen.

\subsubsection{EUS-guided choledochoduodenostomy}

\section{RECOMMENDATION}

ESGE recommends the placement of partially or fully covered self-expandable metal stents or small caliber lumen-apposing metal stents during EUS-guided choledochoduodenostomy.

Strong recommendation, moderate quality evidence.

In EUS-guided choledochoduodenostomy (EUS-CDS), a biliodigestive anastomosis is created with either a biliary metal

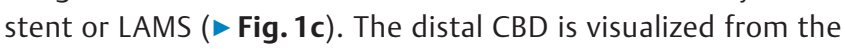
duodenal bulb, and an optimal window for EUS-CDS is sought, avoiding intervening tumor tissue. The CBD is punctured, a cholangiogram performed, and a guidewire placed, facilitating dilation of the tract for stent placement.

Plastic stents, uncovered and covered biliary metal stents, and LAMSs have all been used in performing EUS-CDS ( $\triangleright$ Table 2). Plastic stents and uncovered SEMSs (USEMSs) may however fail to adequately seal the biliodigestive anastomosis and may increase the risk of bile leakage [34]. Studies using FCSEMSs, usually $6 \mathrm{~cm}$ in length, have reported satisfactory outcomes. Partially covered SEMSs (PCSEMSs) have also been used, where anchoring fins and minimal foreshortening of the stent counteract stent migration [35-37].
More recently, all-in-one EC-LAMSs have enabled the performance of direct EUS-CDS, eliminating the need for accessory exchanges, theoretically reducing the risk of procedural failure and AEs. Only small caliber LAMSs should be used for EUS-CDS regardless of the diameter of the CBD. EUS-CDS will significantly reduce the diameter of the CBD and the use of larger caliber LAMSs may result in damage to the CBD wall. Data from one retrospective comparative study and a meta-analysis comparing outcomes with LAMSs versus biliary SEMSs for EUS-CDS have failed however to show significant differences between these two techniques [35, 38].

For EUS-CDS using an EC-LAMS, the free-hand technique allows direct access to the CBD. EUS-CDS using a LAMS may be challenging in small diameter CBDs $(<12 \mathrm{~mm})$, as deployment of the distal flange of the stent inside the duct may be difficult. Two procedural adjustments that may be considered to overcome this limitation are: (i) performing LAMS deployment in a stepwise manner, with the distal flange being opened into the duct in incremental steps; (ii) advancing a guidewire through the LAMS-introducing catheter, which will allow the operator to direct the catheter towards the liver hilum and open the stent flange perpendicular to the main axis of the CBD. 
Table 2 Stents advised for each therapeutic endoscopic ultrasound (EUS) procedure.

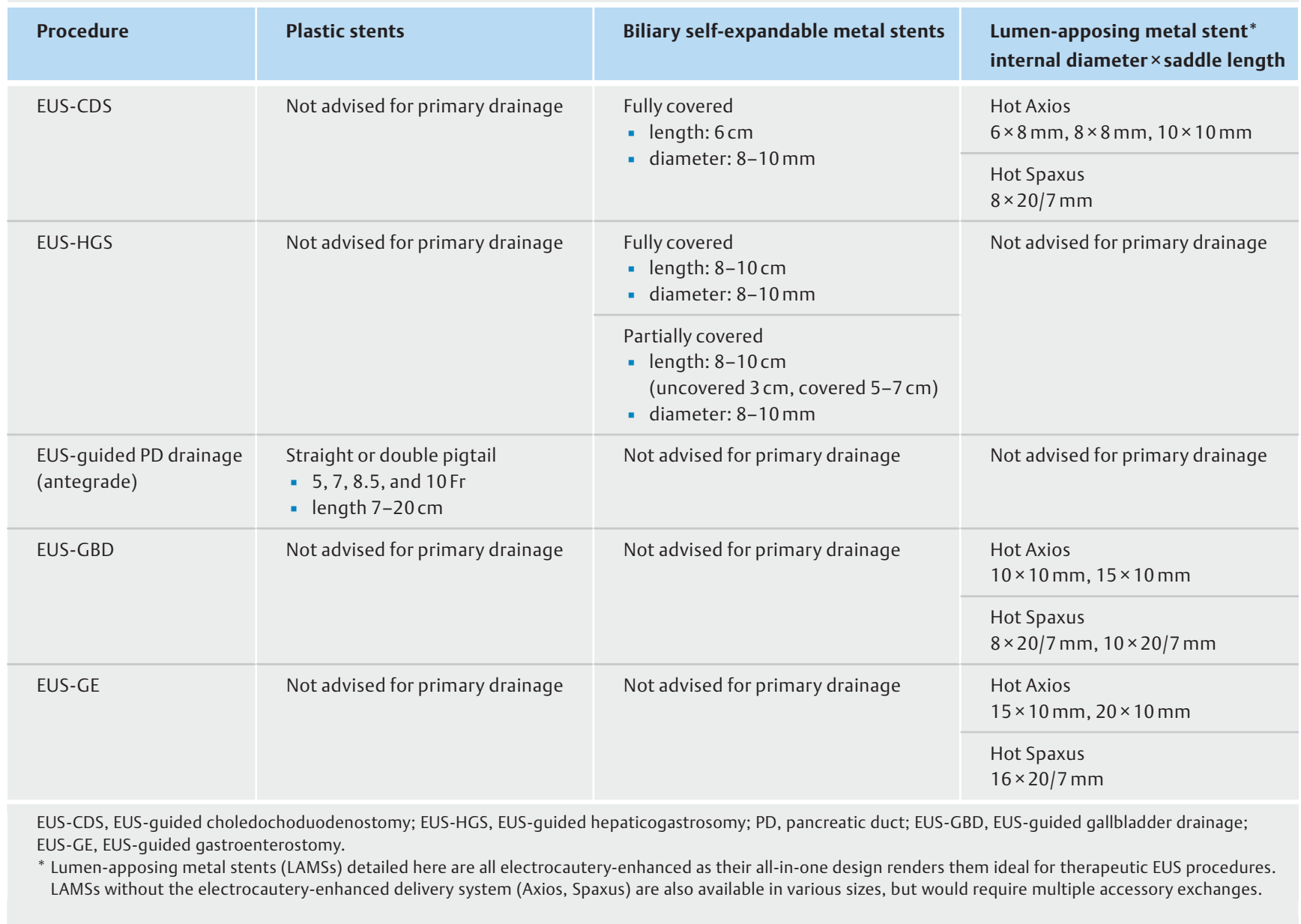

\subsubsection{EUS-guided hepaticogastrostomy}

\section{RECOMMENDATIONS}

ESGE recommends placement of partially or fully covered self-expandable metal stents (SEMSs) during EUS-guided hepaticogastrostomy for biliary drainage in malignant disease.

Strong recommendation, moderate quality evidence.

ESGE recommends temporary placement of fully covered SEMSs during EUS-guided hepaticogastrostomy for biliary drainage in benign disease.

Strong recommendation, low quality evidence.

During EUS-HGS, the dilated intrahepatic bile ducts are visualized from the left liver lobe ( $\bullet$ Fig. 1d). The position of the tip of the echoendoscope should be located in the stomach to prevent inadvertent placement of a SEMS into the esophagus, which may result in dysphagia and vomiting. The basic steps are similar to those for EUS-guided antegrade stent placement. Access is secured by placement of a guidewire through a $19 \mathrm{G}$ needle, deep into the biliary system, over which accessories can be advanced to permit deployment of a stent between the dilated left ductal system and the stomach.

Various types of stents have been used in EUS-HGS. Doublepigtail stents are difficult to place and USEMSs carry an unacceptably high risk of bile leakage. A purposely developed single-pigtail stent for HGS is available in some countries, where excellent outcomes have been reported using these stents $[39,40]$. On the other hand, FCSEMSs may obstruct distal bile duct branches and cause cholangitis, but their removability after fistulous tract maturation makes them especially suitable for benign indications. In this way EUS-HGS may serve as a "portal" to the biliary system, allowing direct cholangioscopyguided lithotripsy, as well as the evaluation of strictures in surgically altered anatomy [41-44].

Standard FCSEMSs appear less suited for long-term drainage because stent dysfunction and dislocation, which may be more common with certain FCSEMS types, may occur in up to $50 \%$ of cases [45]. A hybrid stent has been developed with the aim of improving the outcomes of long-term drainage in malignant settings. It is made of an uncovered $( \pm 30 \%)$ intraductal portion that prevents bile duct branch obstruction, while the remaining part is fully covered to prevent bile leakage at the anastomotic transparietal site [46]. 


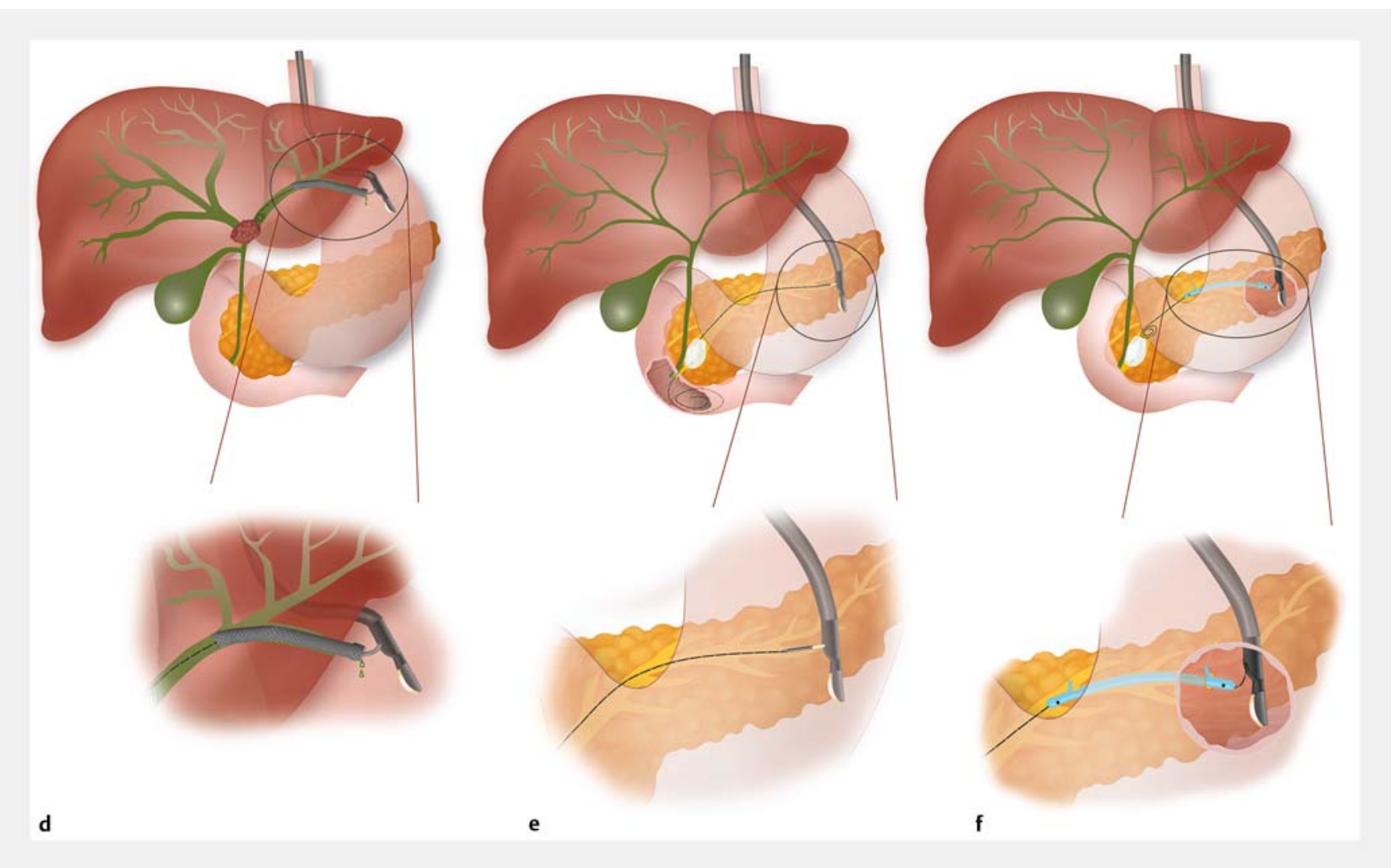

- Fig. 1d-f Illustrations of therapeutic endoscopic ultrasound (EUS) interventions of the pancreaticobiliary and gastrointestinal tract showing: d EUS-guided hepaticogastrostomy; e EUS-assisted rendezvous (pancreas); f EUS-guided pancreaticogastrostomy. Source: Martha Meisen.

When EUS-HGS is performed, it is important to deploy the stent inside the working channel of the scope, whilst simultaneously retracting the scope so that at least $2-3 \mathrm{~cm}$ of the stent protrudes into the gastric lumen to prevent stent migration $[47,48]$. In some instances, when the right and left liver lobes are non-communicating and are disconnected by tumor, it may be possible to place a bridging stent to reconnect both systems to optimize biliary drainage $[49,50]$.

\subsubsection{EUS-guided hepaticoduodenostomy}

\section{RECOMMENDATION}

ESGE recommends EUS-guided hepaticoduodenostomy be performed only at expert centers and after careful consideration of all therapeutic options.

Strong recommendation, low quality evidence.

The right liver lobe can only be partially visualized via the duodenal bulb in the long position. Similarly to EUS-HGS, the bile duct is punctured with a $19 \mathrm{G}$ needle and a cholangiogram performed. After a guidewire has been advanced into the bile duct, a tract is created using a 6-Fr cystotome or dilation balloon. An FCSEMS is placed with the proximal tip in the dilated bile duct and the distal tip about $2-3 \mathrm{~cm}$ inside the duodenum.
There is currently only very limited experience with this technically demanding technique; for this indication PTBD remains the gold standard [51,52].

\subsection{Key question 4: What adverse events may occur when EUS-BD is performed and how should these be managed?}

\subsubsection{Stent maldeployment and perforation}

\section{RECOMMENDATION}

ESGE recommends endoscopic stent-in-stent therapy when maldeployment occurs during EUS-guided hepaticogastrostomy and, if this is not feasible, that percutaneous transhepatic biliary drainage or emergency salvage surgery should be considered.

Strong recommendation, low quality evidence.

Stent maldeployment may lead to bile leakage, which may increase the distance between the duodenum and CBD, preventing a successful second attempt at LAMS placement. In this setting, the CBD defect may be closed by performing EUSRV with placement of an FCSEMS by ERCP, or alternatively EUSguided antegrade stent placement may be performed followed 
by LAMS removal and endoscopic closure of the duodenal defect with the most appropriate clip [53].

EUS-BD performed in a small diameter CBD increases the risk of accidental perforation of the portal vein, which can induce substantial blood loss via the LAMS into the duodenum. The same salvage procedure as described above can ensure resolution of both the CBD and portal vein defects, although hospitalization and close monitoring will be required in such instances, given the potential risk of severe bleeding [54].

Interventional radiology with PTBD should be used if endoscopic salvage therapy fails. In EUS-CDS, this is especially warranted for all punctures crossing the peritoneal cavity. Punctures in the retroperitoneal portion of duodenum and distal CBD may be managed conservatively, as these can usually be resolved by same-session EUS-guided CBD drainage, targeting an area adjacent to the site of the failed attempt.

Stent maldeployment in EUS-HGS usually occurs when the proximal end of the stent is deployed inside the peritoneal cavity, instead of in the gastric lumen, leading to biliary peritonitis that may potentially be fatal [55]. Inadequate stent placement may become apparent when the "candy sign" is observed on fluoroscopy, whereby the liver capsule and gastric wall are not adjacent to each other and appear as two distinct indentations [48]. This can be prevented by applying tension on the delivery catheter and retracting the echoendoscope in a stepwise manner to ensure that the proximal end of the stent opens in the stomach during deployment.

When the proximal end of the stent is still visible in the gastric wall, it can be pulled towards the gastric lumen using a grasping forceps before an additional stent-in-stent is placed to anchor the primary stent and prevent migration [56,57]. If the stent is completely outside the gastric wall but the guidewire is still in place, one may attempt to release a second FCSEMS over the wire in order to bridge the maldeployed stent to the stomach [58]. If this is not possible, access to the dislocated stent can be regained by puncturing it under EUS guidance, followed by guidewire advancement into the liver and placement of a second bridging stent [59]. When these procedures fail, emergency salvage surgery, with repositioning of the stent may be indicated [58]. The principal objective of all salvage procedures should be to achieve bile duct drainage and to secure closure of the puncture defects on both sides of adjacent organs, either by means of surgical drainage or PTBD in order to relieve intraductal pressure, thereby reducing the risk of delayed bile leakage.

Bleeding may occur during the procedure or may be delayed, but in most cases conservative treatment and observation will suffice. Rarely, bleeding can be severe or persistent and interventional radiology management may be required to manage an arteriobiliary fistula.

\subsubsection{Endoscopic treatment of long-term adverse events}

\section{RECOMMENDATION}

ESGE recommends placement of a stent through the metal stent when EUS-guided choledochoduodenostomy or EUS-guided hepaticogastrostomy is complicated by stent occlusion.

Strong recommendation, low quality evidence.

EUS-CDS stents may become occluded by food remnants or sludge, or due to compression of the contralateral wall of the $C B D$, especially when a large diameter LAMS has been used $[60,61]$. LAMSs placed for EUS-CDS have been sporadically reported to migrate, though without bile leakage, which implies that the dislocation has occurred after the fistulous tract had matured $[62,63]$. When the fistula is still open, a new stent can be placed. Double-pigtail plastic stents (DPPSs) may be placed through the metal stent to maintain stent patency [60, 61]. Prophylactic DPPS placement through a LAMS was however not found to improve any procedural outcome in a multicenter retrospective cohort study [64].

Stent occlusion in EUS-HGS can be treated by placing DPPSs or SEMSs coaxially through the occluded metal stent. Stent ingrowth or overgrowth can be addressed by the use of intraductal radiofrequency ablation to regain stent patency. Cannulation of the occluded metal stent can sometimes be challenging if a relatively long portion of the metal stent protrudes into the stomach. In these cases, a small incision made with a needle-knife along the side of the stent, or trimming by argon plasma coagulation (APC) may provide easy access into the stent lumen, which then facilitates further interventions, such as guidewire passage and stent-in-stent placement $[65,66]$.

\subsection{Key question 5: How should EUS-guided PD drainage be performed?}

\subsubsection{General principles of EUS-guided PD}

\section{RECOMMENDATION}

ESGE recommends EUS-guided pancreatic duct drainage should only be performed at high volume expert centers, owing to the complexity of this technique and the high risk of adverse events.

Strong recommendation, low quality evidence.

Chronic pancreatitis-related pain may be due to ductal hypertension caused by obstruction of the main pancreatic duct (MPD) by stones, congenital anomalies, and/or strictures. Ductal decompression represents the main treatment modality and can be provided by endoscopic retrograde pancreatography (ERP) or surgical decompression [67]. In 2007, a randomized comparison of these two techniques showed superior efficacy of surgical drainage, with technical success of ERP 
achieved in only $53 \%$ of cases at an academic expert setting [67]. Surgically altered anatomy, duct disruption, large stones, or tight strictures are all typical causative features leading to ERP failure.

EUS-guided PD drainage facilitates access to the MPD, thereby leading to EUS-guided PD drainage becoming an invaluable rescue procedure when ERP fails [68-70]. EUS-guided PD drainage procedures are however technically demanding and lead to high morbidity in comparison to other therapeutic EUS procedures, and should only be performed in high volume expert centers. The (contra)indications, comparisons with alternatives, and potential AEs have been discussed in the ESGE guideline [1]. The aim of the following sections is to provide guidance on how EUS-guided PD drainage should be performed.

\section{RECOMMENDATION}

ESGE recommends the use of rectal nonsteroidal antiinflammatory drugs in patients undergoing EUS-guided pancreatic duct drainage.

Strong recommendation, low quality evidence.

EUS-guided PD drainage can be done by either EUS-assisted (i.e. rendezvous-assisted ERP [RV-ERP]) or EUS-guided antegrade or transmural approaches. Although no formal comparison exists between these three approaches, it is generally accepted that RV-ERP may hold significant advantages over antegrade or transmural drainage with regards to safety and efficacy $[69,71-73]$. The latter techniques are therefore only recommended in patients where RV-ERP fails or is not technically feasible $[1,68,72]$.

Patients undergoing EUS-guided PD drainage may benefit from rectal nonsteroidal anti-inflammatory prophylaxis and broad-spectrum antibiotics $[69,73-76]$, although this has not been systematically studied.

\subsubsection{Rendezvous-assisted ERP}

After the PD has been accessed with a preflushed 19G or 22G FNA needle under EUS guidance, the anatomy is defined fluoroscopically by contrast injection. A $0.035 / 0.025$-inch or $0.021 /$ 0.018 -inch guidewire is then advanced into the PD ( $>$ Fig. 1e). The use of 22G needles and smaller caliber guidewires is generally discouraged as these wires may not be sufficiently rigid to allow for the advancement of dilation balloons, rigid dilators, and stents $[68,75,77]$. The main goal is to advance the guidewire deep into the duodenum, to achieve a stable transpapillary or transanastomic platform, and prevent guidewire dislocation while the echoendoscope is exchanged for the duodenoscope. During the process of guidewire manipulation, it can be extremely challenging to advance the guidewire beyond stones and/ or strictures. If attempts are unsuccessful, despite extensive guidewire manipulation, a fistulous tract can be created using a 6-Fr cystotome or mechanical dilation. This will allow instruments, such as the cystotome or an ERCP catheter, to be advanced into the $\mathrm{PD}$, which will provide a more stable platform for guidewire manipulation. If the guidewire still cannot be advanced across the stricture or beyond the stone with the aid of the cystotome, this tract may immediately facilitate transmural PD drainage to the stomach or duodenal bulb.

\subsubsection{EUS-guided PD drainage}

\section{RECOMMENDATION}

ESGE recommends rendezvous-assisted endoscopic retrograde pancreatography (RV-ERP) in patients with favorable anatomy, followed by antegrade or transmural EUS-guided pancreatic duct drainage only when RV-ERP fails or is not feasible.

Strong recommendation, low quality evidence.

In patients with surgically altered anatomy, an inaccessible papilla, or where RV-ERP has failed, EUS-guided PD drainage should be considered. Variations of this technique depend on the puncture site and whether a stent will eventually be placed transmurally or in antegrade fashion across an anastomosis or papilla. Variations include pancreaticogastrostomy ( $\triangleright$ Fig. 1f), pancreaticoenterostomy, gastropancreaticoenterostomy (also called "ring drainage"), and pancreaticobulbostomy [71]. The MPD diameter should at least be $4 \mathrm{~mm}$, as this increases the technical success rate and decreases morbidity.

When previous RV-ERP has been attempted, the cystotome tract can be used to perform EUS-guided PD drainage. Various authors have however suggested first attempting non-cauteryassisted tract dilation with rigid dilators or 4-6-mm balloons to prevent potential thermal injury to the pancreas $[69,74,78]$. Following tract preparation, straight plastic stents $(5-10 \mathrm{Fr}$ ) are inserted, depending on the MPD caliber, and may be directed towards the pancreatic tail or head. FCSEMSs have also been successfully used, although only in a small number of patients [79]. Transmural drainage by transgastric or transenteric stent placement will create a pancreaticogastrostomy, pancreaticoenterostomy, or pancreaticobulbostomy, depending on the scope position, anatomy, and needle access.

In gastropancreaticoenterostomy or "ring drainage," a pancreaticogastrostomy and pancreaticoenterostomy are created simultaneously by passing the distal end of the DPPS through the papilla or anastomosis into the small bowel and deploying the proximal end into the gastric lumen, creating a secure gastropancreaticoenterostomy [74]. For this technique, transpapillary or transanastomotic access is required, but it carries significant advantages compared with the classic pancreaticogastrostomy or pancreaticoenterostomy techniques owing to the double-sided drainage and secure DPPS placement, which prevents migration [69]. 


\subsection{Key question 6: What are the adverse events and possible rescue procedures in EUS-guided PD drainage?}

\subsubsection{Intraprocedural challenges and rescue procedures}

Accessing the MPD with a 19G-needle can be challenging owing to significant pancreatic fibrosis and/or calcified parenchyma, which can complicate smooth needle insertion, tract dilation, and stent placement [74]. In such patients, or where the MPD is only minimally dilated, a 22 G FNA needle may prove more successful in accessing the MPD; however, it only allows insertion of a 0.018 -inch guidewire, which is often inadequate, as described above for other techniques $[68,80]$.

Guidewire access may be extremely difficult because of large MPD obstructing stones. Preprocedural stone fragmentation by extracorporeal shockwave lithotripsy may potentially improve the technical and clinical success rates of RV-ERP [81, 82]. The most crucial steps during RV-ERP require successful advancement of the guidewire across strictures/stones deep into the duodenum, followed by careful exchange of the echoendoscope for a duodenoscope, avoiding guidewire dislocation.

For EUS-guided PD drainage specifically, the difficulty lies in the ability to dilate the transmural tract sufficiently to insert a stent deep enough into the MPD to prevent stent dislocation $[69,74]$. In the unfortunate situation where the plastic stent dislocates beyond the gastric wall during EUS-guided PD drainage, a snare over the guidewire or a digital cholangioscope may be used in an attempt to recover the stent. If the MPD is successfully punctured but subsequent drainage fails, the risk for the development of peripancreatic collections increases and may become evident only over the ensuing days. These patients should be observed more closely, the antibiotic course extended, and transgastric drainage considered, especially if these collections become symptomatic or infected.

\subsubsection{Endoscopic treatment of long-term adverse events}

Most AEs are known to occur immediately following unsuccessful drainage, while limited long-term safety data are available [63]. In RV-ERP, classic stent exchanges are required with reinterventions scheduled every 3-6 months [81]. Long-term AEs in this group are therefore related to ERP only. Antegrade approaches, such as pancreaticogastrostomy and pancreaticobulbostomy, are known to exhibit a significant risk of stent dysfunction over time owing to obstruction and/or migration [78]. In one of the initial retrospective studies reporting EUS-guided PD drainage $(n=36)$, clinical success was obtained in $69.4 \%$ of patients, although in $55 \%$ stent dysfunction occurred after a mean follow-up of 14 months [73]. Stent exchange management among experts varies from scheduled exchanges every 6 months to exchanges "on-demand" when symptoms recur. Migration can be problematic in these patients, as the MPD diameter will have decreased, complicating repeat EUS-guided PD drainage. In this population, few further therapeutic options currently exist, given the low technical success associated with ERP and the difficulties associated with rescue surgery.

\section{Gallbladder drainage}

EUS-guided gallbladder drainage (EUS-GBD) has become a valuable alternative for patients with acute cholecystitis at high surgical risk, with several demonstrated advantages compared with percutaneous and transpapillary drainage [83-89]. In addition to its use within the context of acute cholecystitis, this technique can also be considered as a rescue procedure in patients with unresectable distal malignant biliary obstruction in the exceptional case of failed ERCP, PTBD, or EUS-BD [90, 91].

The indications for EUS-GBD have become more clearly defined and are discussed extensively in the ESGE guideline on therapeutic EUS [1]. This section is aimed at providing a framework on the various techniques for performing EUS-GBD and will discuss the roles of DPPSs and complete stone clearance, as well as subsequent rescue procedures in the advent of a complication.

\subsection{Key question 7: How should EUS-GBD be performed?}

\subsubsection{LAMS placement}

\section{RECOMMENDATIONS}

ESGE suggests the use of an electrocautery-enhanced lumen-apposing metal stent (LAMS) or dedicated SEMS in EUS-guided gallbladder drainage (EUS-GBD), given their enhanced ease of use and safety compared with alternatives.

Weak recommendation, low quality evidence.

ESGE suggests performing transduodenal EUS-GBD with a LAMS, rather than using the transgastric route, as this may reduce the risk of stent dysfunction.

Weak recommendation, low quality evidence.

The initial studies in the management of acute cholecystitis using EUS-GBD used fully or partially covered SEMSs and plastic stents, and showed high clinical success rates [88]. However, plastic stents were associated with higher AE rates when compared with the placement of LAMSs, and both stent types required more procedural steps [88].

EUS-GBD using LAMSs was derived from EUS-guided drainage of pancreatic fluid collections and EUS-CDS [90-95]. The gallbladder is located, either from the distal stomach or duodenal bulb, using EUS, and an FNA needle (either 22 G or 19G) can then be used to aspirate gallbladder content, inject contrast to fluoroscopically define the anatomy, and to introduce a 0.025 inch or 0.035 -inch guidewire, over which the LAMS will be placed $[85,96-99]$. More commonly, an EC-LAMS is placed using the "free-hand" technique in one single step ( $\mathbf{F i g . 1 g}$ ), which has been reported to reduce the procedural time $[85,96$, $100,101]$. It is imperative to ensure that the distal flange is sufficiently pulled back to approximate the gallbladder wall against the duodenal or gastric wall before slowly releasing the stent. 

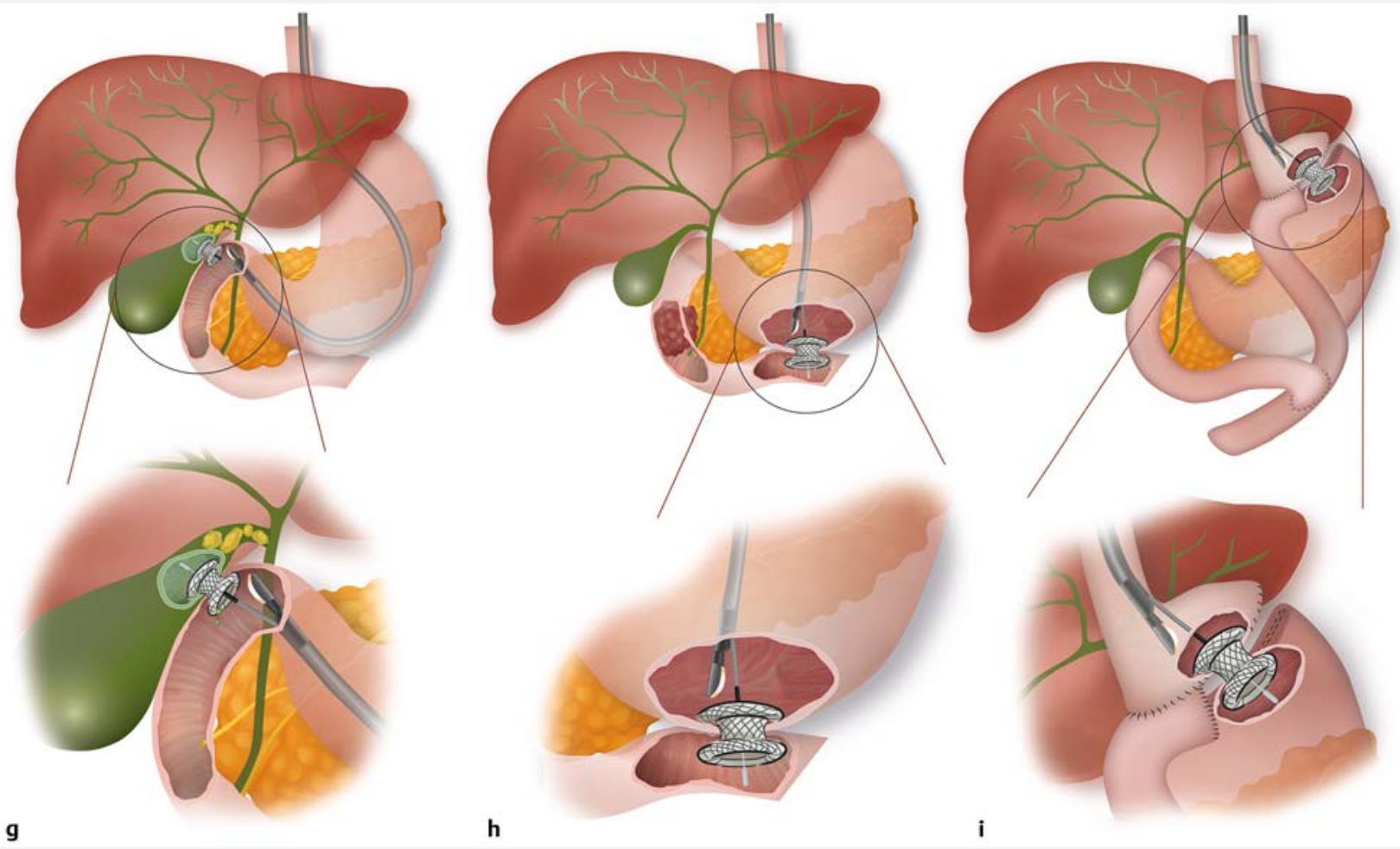

Fig. 1g-i Illustrations of therapeutic endoscopic ultrasound (EUS) interventions of the pancreaticobiliary and gastrointestinal tract showing: g EUS-guided gallbladder drainage; h EUS-guided gastroenterostomy; i EUS-guided gastrogastrostomy. Source: Martha Meisen.

With both techniques, care should be taken to adjust the puncture distance to the LAMS saddle length, which in most cases should not exceed $15 \mathrm{~mm}$ and preferably be a short as possible $(\vee$ Table 1$)$. In the exceptional case where the puncture distance exceeds $15 \mathrm{~mm}$ and EUS-GBD is deemed necessary, the gallbladder lumen may be filled with saline or placement of a covered SEMS may be considered. Alternatively, given the increased potential risk of misplacement, the procedure may be aborted, with the patient referred for percutaneous drainage.

Transduodenal access is usually preferred over transgastric EUS-GBD, as antral LAMS placement has been associated with more symptom recurrence owing to food impaction and a higher risk of a buried LAMS $[96,98,100]$. Notably, no head-to-head comparisons have been performed between the two EUS-GBD drainage routes, with placement often governed by the most stable echoendoscope position.

Patient-related factors, such as the interposition of vessels, malignant duodenal obstruction, more optimal apposition, or even improved ergonomics for the endoscopist, can be valid reasons to settle for transgastric LAMS placement [102].

\subsubsection{LAMS diameter}

Several landmark papers have based their selection of LAMS diameter on the size of the gallbladder stones to allow for stone evacuation following placement: when stones are smaller than $10 \mathrm{~mm}$, a $10-\mathrm{mm}$ LAMS would suffice; when stones are larger than $10 \mathrm{~mm}$, a $15-\mathrm{mm}$ LAMS, but no larger, should be considered $[84,85,103]$. When the gallbladder is not sufficiently dilated or is filled with multiple large stones, it may not be feasible to safely deploy a 15-mm LAMS. In these cases, a smaller caliber LAMS should be placed to resolve cholecystitis. When it is not feasible to place a LAMS because of stones that would prohibit deployment, the gallbladder can be punctured with a 19G FNA needle and filled with saline in order to induce sufficient distension to facilitate stent deployment.

Regardless of the stone size, some patients with a longer expected survival time may benefit from re-intervention aimed at treating residual stones $[92,96,104]$. Clearing gallbladder stones, with or without the use of lithotripsy, and replacing the LAMS with DPPSs may potentially prevent LAMS-related AEs and preclude future biliary events. In this specific context, a 15-mm LAMS, as opposed to a 10-mm LAMS, will more readily accommodate transluminal endoscopic re-interventions. 


\subsubsection{Stent dysfunction}

\section{RECOMMENDATION}

ESGE suggests considering pre-emptive placement of coaxial double-pigtail plastic stents in patients with a higher expected risk of SEMS or LAMS occlusion.

Weak recommendation, low quality evidence.

Some patients are at increased risk of LAMS obstruction. This is especially the case in patients with a high stone burden or who have had a LAMS inserted through the stomach, where food impaction may lead to an increased risk of stent dysfunction $[96,98]$. In these situations, coaxial placement of DPPSs may be considered to prevent stent occlusion by stones or food debris. Few efficacy data are currently available to systematically support this approach $[85,98,99]$.

\subsubsection{Stone clearance and LAMS replacement}

\section{RECOMMENDATION}

ESGE suggests considering complete stone clearance and LAMS exchange for double-pigtail plastic stents when long-term drainage is required after EUS-guided gallbladder drainage.

Weak recommendation, low quality evidence.

Gallbladder stones may persist in almost half of cases following EUS-GBD [96]. Peroral cholecystoscopy through the LAMS provides the unique opportunity to evaluate the luminal surface of the gallbladder and permits complete stone clearance, potentially reducing future biliary events in patients who require prolonged gallbladder drainage $[92,96,104]$. These procedures can be performed as soon as 1-2 weeks after LAMS placement, although most data suggest that postponing stent removal to 4 weeks may be ideal $[85,92,96]$. Access through the EUS-GBD tract may sometimes require LAMS removal, with or without balloon dilation of the fistulous tract, to facilitate passage of the devices to aid in stone removal. Various endoscopic devices can be introduced to retrieve stones, ranging from a basket to tripods [103]. In some instances, multiple lithotripsy sessions may be required to achieve complete stone clearance.

Limited data exist regarding the long-term efficacy and safety of EUS-GBD with a LAMS. Consequently, several authors have suggested that LAMSs should be exchanged after stone removal and replaced with a DPPS (7-10 Fr), provided that there is enough residual gallbladder lumen to accommodate these stents [85, 92, 96, 99, 104].

In patients with a limited expected survival time or advanced malignant disease, EUS-GBD can be used as a definitive therapy without further surveillance. To date, no comparative studies have been performed to compare the outcomes between these different approaches.

\subsection{Key question 8: What are the adverse events and possible rescue procedures in EUS-GBD?}

Overall AEs following EUS-GBD vary, with most studies reporting rates between $8 \%$ and $18 \%[83,94,97,105]$. Bleeding, stent migration, capnoperitoneum, and stent occlusion with recurrent cholecystitis represent the most frequent $A E s$ following EUS-GBD [83, 94, 97].

Recurrent cholecystitis has been reported in up to $8 \%$ of cases following LAMS placement and is mostly related to either LAMS obstruction or a "buried" LAMS [106]. The risk may be reduced by intraduodenal LAMS placement, use of coaxial DPPSs, and/or planned re-interventions with stone clearance [85, 92 , $96,99,104]$.

Intraprocedural bleeding near the puncture site is generally minimized by tamponade from the LAMS. Extraluminal bleeding due to trauma to the cystic artery is rare, but requires embolization [97].

Other AEs associated with maldeployment that may occur include perforation, bile leak, and peritonitis, all of which may require urgent surgery $[93,94,106-110]$. If only the gastric or duodenal wall is perforated and the gallbladder is still intact, immediate endoscopic closure with an over-the-scope (OTS) clip can be considered. If endoscopic salvage has been successfully performed, capnoperitoneum can usually be treated conservatively, but transabdominal needle decompression may be required in cases of tension capnoperitoneum [111].

If stent deployment fails after the gallbladder has already been punctured by a LAMS, it will be imperative to proceed to either emergency percutaneous gallbladder drainage or surgery as bile leakage is inevitable and may result in potentially fatal peritonitis.

\section{Gastrointestinal anastomoses}

EUS-guided gastroenterostomy (EUS-GE) is used in the management of gastric outlet obstruction (GOO) and afferent loop syndrome [1]. The next sections provide guidance on how EUSGE procedures should be performed. EUS-guided gastrogastrostomy has also been developed to facilitate ERCP in the setting of Roux-en-Y gastric bypass (RYGB), commonly referred to as the EDGE procedure (EUS-directed transgastric ERCP).

\subsection{Key question 9: How should EUS-GE procedures be performed?}

\subsubsection{General principles for the creation of EUS-GE} anastomoses

There are currently no definitive guidelines nor consensus on the preprocedural management of patients undergoing EUSguided lumen-to-lumen anastomoses. However, similarly to other endoscopic procedures in patients with GOO, the following preprocedural precautions would apply. Patients should be kept on a clear liquid diet for a few days before the procedure and "nil per mouth" 24 hours before performing EUS-GE, to minimize the presence of residual gastric content and the risk of aspiration. A large-bore nasogastric tube may be needed to 
clear the stomach contents in some patients with persistent vomiting despite being maintained on a clear fluid diet.

Post-procedurally, patients should ideally be hospitalized overnight for observation, even though there is currently no consensus; in some high volume centers, patients with no post-procedural abdominal pain are discharged the same day. Some experts advise 24 hours of fasting before initiating a clear liquid diet. In the days following the procedure, this can be slowly broadened as tolerated up to a normal diet [112]. In some centers, in the absence of pain, fluid intake is permitted within hours after the procedure, and rapidly escalated to a liquid and soft low-fiber diet thereafter. With the availability of the 20 -mm LAMS, most patients may ultimately return to normal diets. The routine use of proton pump inhibitors in these patients is not supported by any evidence.

\section{RECOMMENDATION}

ESGE recommends using saline instillation for small-bowel distension during EUS-guided gastroenterostomy. Strong recommendation, low quality evidence.

Various techniques have been developed to create an EUSGE aimed at overcoming two main difficulties: (i) locating the segment distal to the GOO; (ii) stabilizing the targeted loop for subsequent puncture and stent introduction. A crucial step in the successful performance of EUS-GE is providing sufficient dilation of the target loop. A nasojejunal feeding tube or nasobiliary catheter that contains more side holes and infuses larger volumes of saline is placed across the stricture beyond the ligament of Treitz over a previously placed guidewire. Alternatively, saline is instilled into the small bowel directly through the endoscope by placing it at the level of the stricture [113]. For either the catheter- or endoscope-based technique, saline is instilled using prefilled syringes or a waterjet. Dye can be added to the mixture (most often methylene blue or indigo carmine) to allow for visual confirmation of successful LAMS placement when the proximal flange opens into the stomach. Furthermore, contrast can be mixed with saline in order to fluoroscopically depict the small-bowel anatomy. In general, 250-500 mL of saline is needed to achieve sufficient distension of the target segment, although this may vary. Intravenous administration of antimotility agents, such as butyl scopolamine or glucagon $(0.5-3.0 \mathrm{mg})$, can be considered to decrease intestinal contractions.

\subsubsection{Direct EUS-GE technique}

\section{RECOMMENDATIONS}

ESGE recommends the use of electrocautery-enhanced LAMSs in EUS-guided gastroenterostomy.

Strong recommendation, low quality evidence.

ESGE recommends the use of LAMSs of at least $15 \mathrm{~mm}$ in diameter in EUS-guided gastroenterostomy. Strong recommendation, low quality evidence.

A linear echoendoscope is introduced and positioned under fluoroscopic and EUS guidance to visualize the intended smallbowel loop. A transgastric puncture is performed with a $19 \mathrm{G}$ FNA needle and the small-bowel loop is filled with saline mixed with contrast. The endoscopist can then proceed with placement of a guidewire through the FNA needle, over which the electrocautery tip of the LAMS is advanced into the jejunum, using the Autocut setting. Alternatively, the FNA needle can be removed and the electrocautery-tipped delivery device (Autocut 100-150 W, effect 3-5) can be advanced into the jejunum using the "free-hand" technique ( $\triangleright$ Fig. 1h). LAMS insertion over the wire has mostly been abandoned as this may push the jejunum further away, which may lead to stent maldeployment. Should the endoscopist still elect to perform over-the-wire placement, we advise slow withdrawal of the guidewire when advancing the EC-LAMS to minimize displacement of the jejunum. After the delivery device is confirmed to be inside the lumen of the jejunum on EUS, the distal flange is deployed. The device is then gently retracted, approximating the small-bowel wall to the gastric wall before releasing the proximal flange under EUS or endoscopic control.

\subsubsection{Wireless endoscopic simplified technique}

After the small bowel distal to the GOO has been filled with saline, a linear echoendoscope is advanced into the stomach. After the saline filled duodenum/jejunum has been located, the electrocautery tip is advanced directly using a free-hand technique into the targeted small-bowel lumen under EUS control, without the aid of an FNA needle or guidewire ( $\triangleright$ Fig. $\mathbf{~ h}$ ). The same deployment steps described above are followed to release the stent $[112,114]$.

\subsubsection{Assisted EUS-GE techniques}

Assisted EUS-GE techniques refer to approaches using dilation balloons or double-balloon devices that are inserted through a gastroscope or enteroscope (e.g. endoscopic ultrasoundguided double-balloon-occluded gastroenterostomy bypass; EPASS) [115-117]. In the balloon-assisted technique, a guidewire is inserted across the GOO and the balloon catheter is advanced under fluoroscopic guidance into the jejunum. Under EUS guidance, the fluid-filled balloon or occluded jejunal segment is punctured with a 19G FNA needle and a guidewire is advanced into the jejunal lumen. A LAMS is then inserted and deployed over the guidewire. 


\subsubsection{What size LAMS should be used to create an EUS-GE?}

For EUS-GE, both 15-mm and 20-mm LAMSs have been used. The diameter of surgically created gastroenterostomies ranges between 25 and $35 \mathrm{~mm}$. Therefore, from a theoretical standpoint, a $20-\mathrm{mm}$ LAMS should be preferred. Comparative data are limited, although a recent retrospective study demonstrated improved clinical efficacy with 20 -mm stents compared with 15-mm stents [112].

\subsection{Key question 10: How should EDGE procedures be performed?}

EUS-directed transgastric ERCP (EDGE) can be offered to patients with RYGB in expert centers in an attempt to overcome the invasiveness of laparoscopy-assisted ERCP and the limitations of enteroscopy-assisted ERCP [1]. This section is aimed at providing technical guidance regarding EDGE, the timing of subsequent ERCP, and management following successful therapy.

\subsubsection{What is the optimal technique to perform an EDGE procedure?}

\section{RECOMMENDATION}

ESGE recommends the use of saline instillation with a $19 \mathrm{G}$ needle and an electrocautery-enhanced LAMS for EDGE procedures.

Strong recommendation, low quality evidence.

In 2011, prior to the development of LAMSs, a percutaneous approach was developed using insufflation of the gastric remnant via a $19 \mathrm{G}$ needle, followed by subsequent placement of a 16 -Fr PEG gastrostomy. Through this percutaneous route, ERCP could be performed [118-120]. This first attempt provided the basis for the subsequent development of a completely endoscopic approach.

The advent of LAMSs has led to the development of an endoscopic technique to join the excluded stomach to the gastric pouch, with the formation of a stable anastomosis, under EUS guidance. This creates a conduit through which a duodenoscope can be inserted [121]. Once the excluded stomach has been located by the echoendoscope positioned in the pouch or proximal jejunum, a $19 \mathrm{G}$ needle is advanced and $250-500 \mathrm{~mL}$ of saline, with or without dye, is instilled, until the excluded stomach is adequately distended. The needle is then retracted and the EC-LAMS is advanced into the excluded stomach lumen under sonographic control. Although an over-the-wire placement has been reported, the "free-hand" technique is nowadays mostly employed and the stent is released in the same way as for EUS-GE ( $\triangleright$ Fig. 1i) [122-124]. Care should be taken not to deploy the LAMS too caudally in the antrum or distal gastric body, as this may complicate subsequent insertion of the duodenoscope.

\subsubsection{Is there a preference for LAMS diameter?}

\section{RECOMMENDATION}

ESGE recommends the use of either 15- or 20-mm LAMSs for EDGE, with a preference for 20-mm LAMSs when considering a same-session ERCP.

Strong recommendation, low quality evidence.

In a recent large multicenter retrospective analysis of 178 EDGE procedures, the use of a smaller caliber 15-mm LAMS was an independent risk factor for intraprocedural stent dislodgement [125]. Placement of a $20-\mathrm{mm}$ stent is therefore preferred as it provides easier access for the duodenoscope into the gastric remnant, which decreases the risk of stent migration. Placement of a 20-mm LAMS is strongly advised when a same-session ERCP is considered, with balloon dilation to facilitate safe passage of the duodenoscope through the stent.

\subsubsection{What is the optimal time that should be allowed before performing an ERCP following LAMS placement?}

\section{RECOMMENDATION}

ESGE suggests considering a delay of at least 7 days before performing ERCP following EDGE whenever possible. Weak recommendation, low quality evidence.

In early 2021, a systematic review showed that intraprocedural stent migration occurred in $16 \%$ of EDGE procedures and was mainly due to stent dislodgement when a same-session ERCP was performed [126]. A recent study suggested that large caliber 20-mm LAMSs and stent fixation techniques may allow for safe same-session ERCP compared to smaller 15-mm stents [127]. When permitted, a low risk strategy can be adopted by delaying ERCP for up to 7 days following LAMS placement, which allows the gastrogastrostomy LAMS to fully expand and the fistulous tract to mature. However, for patients with cholangitis or in other urgent settings, a same-session ERCP should always be considered. This can be accomplished by adequate balloon dilation at least up to $15 \mathrm{~mm}$ to allow the duodenoscope to be carefully manipulated through the LAMS. Overdilation of the stent should however be avoided. Anchoring techniques, such as clipping or suturing, have also been reported to prevent migration when same-session ERCP is required $[125,128]$, although a recent large retrospective analysis did not identify fixation techniques as beneficial in preventing this AE [127]. 


\subsubsection{When should the LAMS be removed and should endoscopic closure be provided?}

\section{RECOMMENDATION}

ESGE recommends that LAMSs should not be removed within the first 7 days of placement and thereafter only when no additional pancreaticobiliary interventions are required.

Strong recommendation, low quality evidence.

LAMSs should be removed when no additional re-interventions are required, although some patients may benefit from leaving the stent for longer periods. Many methods have been described to close the gastrogastric or jejunogastric fistulous tract, although various studies suggest that these tracts may spontaneously close in most cases. Wang and colleagues proposed the technique of "spontaneous closure guided by double-pigtail plastic stents," with an efficiency of more than $70 \%$ [129], whilst James and co-workers applied APC to the margins of the fistula tract in order to promote re-epithelialization and closure [130]. In their study, 61\% of fistulas "spontaneously" closed thereafter. Some authors propose suturing or APC followed by OTS clip placement in cases of failed closure. Kedia et al. used an OTS clip system to close the gastrogastric or jejunogastric fistula after removal of the LAMS, although this may seldom be required [121].

LAMSs should be removed as soon as it becomes apparent that no additional pancreaticobiliary interventions will be required. Practices around the world are diverse, varying from systematic follow-up by upper GI series 8 weeks after LAMS removal, to immediate closure, to no follow-up or closure only in the setting of weight gain. More prospective data are required in this specific context. Until such data become available, in patients with symptoms or weight gain, the presence of an open fistulous tract should be confirmed, either by upper GI series or endoscopy, prior to definitive closure.

\subsection{Key question 11: What are the adverse events and possible rescue procedures in EUS-guided gastrointestinal anastomoses?}

\subsubsection{Stent maldeployment}

LAMS maldeployment can be decreased by careful patient selection and use of proper endoscopic techniques $[5,28,131$ 137]. In the largest available retrospective study on EUS-GE, performed in 16 expert centers, distal or proximal LAMS flange maldeployment occurred in 44 out of 467 patients (9.4\%) [138]. This AE was endoscopically managed in the majority of cases, with success largely dependent on its immediate recognition during the procedure. Indeed, surgery was required in only five patients (11.4\%) [138]. A high index of suspicion for stent maldeployment should be considered especially under the circumstances presented in $>$ Table 3 [28]. Needle decompression of the capnoperitoneum may be necessary and systemic broad-spectrum antibiotics should be administered. In
- Table 3 Circumstances when a high index of suspicion for stent maldeployment should be considered.

1 Appearance of pneumoperitoneum on fluoroscopy immediately after distal flange deployment

2 Failure of the distal flange to anchor to the small bowel or excluded stomach, with it being impossible to advance a guidewire into its lumen (guidewire appearing extraluminal and intraperitoneal on fluoroscopy)

3 No evidence of previously infused blue-tinged fluid flowing into the stomach after full deployment of the stent

4 Lack of visualization of the target luminal structure through the stent on the contralateral side after balloon dilation of the central part of the LAMS

5 Endoscopic visualization of the peritoneum through the LAMS

LAMS, lumen-apposing metal stent.

- Table 4 Steps that can be performed for endoscopic management of intraprocedural stent dislodgement.

1 Maintain the guidewire in the gastric remnant with over-the-wire exchange of the duodenoscope/echoendoscope with a therapeutic gastroscope

2 Perform complete LAMS dilation, if not performed before

3 In cases with complete LAMS dislodgement, the LAMS should be removed

4 In cases with incomplete LAMS dislodgement, an attempt should be made to reposition the misdeployed flange using a grasping forceps, which can be highly effective when there is a mature anastomotic tract

5 In cases with LAMS misdeployment, insert (through the previously positioned LAMS, if still in place) a fully covered esophageal stent or a new LAMS of the same or larger size to bridge both wall defects; this can be further secured by placing double-pigtail plastic stents through it

6 When the guidewire is lost, enter the peritoneal cavity with a therapeutic gastroscope and search for the excluded stomach perforation. Once detected, a transfistula guidewire should be inserted, followed by NOTES techniques to complete the procedure, as highlighted for stent maldeployment cases

7 Fluoroscopic confirmation of the absence of a leak should be obtained at the end of the procedure

LAMS, lumen-apposing metal stent; NOTES, natural orifice transluminal endoscopic surgery.

cases where the stent cannot be bridged or the defect cannot be securely closed, surgical management should be undertaken with removal of the LAMS, closure of the defect, and creation of a surgical anastomosis. This may be challenging for the surgeon in the setting of surgically altered upper Gl anatomy and may require conversion to an open procedure $[121,136$, $139,140]$.

Diagnostic laparoscopy may be warranted when there is doubt about puncture of the duodenum or jejunum with an EC-LAMS. Whereas closure of the stomach is usually easily man- 
aged endoscopically, it is more challenging to recognize the level of a duodenal or jejunal injury. Delayed perforations at the level of the enteric access point may occur late due to thermal necrosis. In fragile patients with a short-term poor overall prognosis, stent maldeployment may be fatal, even if salvaged endoscopically [141].

Maldeployment of a stent into the colon is usually recognized late, after the patient has developed diarrhea associated with meals. Surgery is generally not required, as simple stent removal and endoscopic fistula tract closure may be performed once the fistula and anastomotic tract have matured (typically after 7 days or more).

With EDGE, intraprocedural LAMS dislodgement is a common $A E$, almost entirely related to same-session ERCP. Its severity is related to the lack of a mature fistulous tract, which results, if not recognized, in free perforation. Most cases can be managed endoscopically as long as guidewire access to the remnant stomach is preserved [121].

The endoscopic actions presented in $>$ Table 4 may be useful to salvage a situation where maldeployment has occurred [121, $123,126,129,142-146]$. There are a few reports where perforation could not be managed endoscopically and surgical repair was necessary, with no related fatalities reported thus far $[121,126,142,144,146,147]$.

\subsubsection{Management of intra- and post-procedural bleeding}

Intra- or post-procedural hemorrhage is a rare AE encountered in EUS-guided lumen-to-lumen anastomoses. It can be a direct consequence of: (i) fistula creation [148], (ii) LAMS balloon dilation [149], or (iii) LAMS-induced ulcer or erosion of the GI tract mucosa $[139,149,150]$. For the latter, standard endoscopic hemostatic techniques are usually highly effective, in association with proton pump inhibitor administration. Rarely, LAMS removal or exchange is needed. Intraprocedural bleeding following LAMS dilation can be successfully treated by balloon tamponade or through-the-scope SEMS placement to compress the bleeding vessel [151]. When conservative measures fail, especially in cases of extraluminal bleeding, emergent angiography with vessel embolization is usually effective, while surgical exploration is rarely needed.

\subsubsection{Endoscopic treatment of long-term adverse events}

\section{RECOMMENDATION}

ESGE suggests long-term clinical follow-up and/or intermittent stent surveillance, with or without stent exchange, after EUS-guided gastroenterostomy for benign disease.

Weak recommendation, low quality evidence.

Long-term AEs in EUS-guided lumen-to-lumen anastomoses include stent migration $[126,142,149]$, obstruction by food residue [149], and tissue ingrowth [150] or overgrowth [140]. Recurrence of GOO symptoms, requiring a repeat procedure, occurs in $9 \%-11.4 \%$ of EUS-GE procedures $[152,153]$. How- ever, long-term data on procedural outcomes beyond several months are scanty, which is an important consideration, especially in the management of benign GOO [154]. Cases of stent obstruction can be managed by endoscopic clearance of debris/ food, by stent removal and replacement, or by insertion of a second stent bridging the initially placed LAMS $[140,149]$.

In patients with benign GOO, LAMS removal should be considered if the initial obstruction has resolved, as proven by upper Gl series or cross-sectional imaging studies. Otherwise, clinical follow-up or intermittent stent surveillance (with or without exchange) should be performed at regular intervals [149]. For most malignant indications, stents should be left in place indefinitely, as stenosis/closure of the anastomotic tract would likely occur after stent removal [155].

\section{Disclaimer}

The legal disclaimer for ESGE guidelines [156] applies to this technical review.

\section{Acknowledgements}

The authors would like to sincerely thank Professor Marianna Arvanitakis, Hôpital Erasme Brussels, and Professor Takao Itoi, Tokyo Medical University, for their review of this manuscript. The authors are furthermore grateful for the valuable comments provided by Dr. Huseyin Ataseven (Necmettin Erbakan University, Konya, Turkey) on behalf of the Turkish Society of Gastroenterology, Dr. Rodica Gincul on behalf of the French Society of Digestive Endoscopy, Prof. Frédéric Prat (Université de Paris et Inserm U1016, France), and Dr. Rogier Voermans (Amsterdam UMC, The Netherlands). The authors would also like to acknowledge Martha Meisen for providing the illustrations.

\section{Competing interests}

M. Barthet has received a research grant from Boston Scientific (2015 to present). K.F. Binmoeller has received fees for training and education from Boston Scientific (2015 to present). M. Bronswijk has consultancy agreements with Prion Medical and Taewoong Medical (both ongoing). M.A. Khashab receives consultancy fees from BSCl, Medtronic, Olympus, Pentax, GI Supply, and Apollo (all ongoing). A. Larghi has received consultancy fees from Boston Scientific and Pentax Medical, and educational fees from Taewoong Medical; he receives research support from Medtronic. R. Law receives consultancy fees from Medtronic (2020 to present) and Conmed (2021). M. PerezMiranda receives consultancy fees from Lumendi and Olympus (both 2020 to present) and consultancy and speaker's fees from Boston Scientific (2021). S. van der Merwe has received consultancy fees from Boston Scientific and Cook Endoscopy (both 2012 to present); he was the Boston Chair in Interventional Endoscopy (2018 to 2021) and is the Cook Chair in Portal Hypertension (2021). J.E. van Hooft has received lecture fees from Medtronics (2014, 2015, and 2019), Cook Medical (2019), and Abbivie (2021), and consultancy fees from Boston Scientific (2014 to 2017) and Olympus (2021); her department received research support from Abbott (2014 to 2017) and Cook Medical (2014 to 2019). P.G. Arcidiacono, A. Badaoui, S. Everett, T. Hucl, R. Kunda, S. Lakhtakia, M. Rimbas, and R.L.J. van Wanrooij declare that they have no conflict of interest. 


\section{References}

[1] van der Merwe SW, van Wanrooij RLJ, Bronswijk M et al. Therapeutic endoscopic ultrasound: European Society of Gastrointestinal Endoscopy (ESGE) Guideline. Endoscopy 2021: doi:10.1055/a-1717-1391

[2] Arvanitakis M, Dumonceau JM, Albert J et al. Endoscopic management of acute necrotizing pancreatitis: European Society of Gastrointestinal Endoscopy (ESGE) evidence-based multidisciplinary guidelines. Endoscopy 2018; 50: 524-546

[3] Guyatt G, Oxman AD, Akl EA et al. GRADE guidelines: 1. Introduction-GRADE evidence profiles and summary of findings tables. J Clin Epidemiol 2011; 64: 383-394

[4] Attasaranya S, Netinasunton N, Jongboonyanuparp T et al. The spectrum of endoscopic ultrasound intervention in biliary diseases: a single center's experience in 31 cases. Gastroenterol Res Pract 2012; 2012: 680753

[5] Jovani M, Ichkhanian $\mathrm{Y}$, Parsa $\mathrm{N}$ et al. Assessment of the learning curve for EUS-guided gastroenterostomy for a single operator. Gastrointest Endosc 2021; 93: 1088-1093

[6] Poincloux L, Rouquette O, Buc E et al. Endoscopic ultrasound-guided biliary drainage after failed ERCP: cumulative experience of 101 procedures at a single center. Endoscopy 2015; 47: 794-801

[7] Tyberg A, Mishra A, Cheung M et al. Learning curve for EUS-guided biliary drainage: What have we learned? Endosc Ultrasound 2020; 9: 392-396

[8] Oh D, Park DH, Song TJ et al. Optimal biliary access point and learning curve for endoscopic ultrasound-guided hepaticogastrostomy with transmural stenting. Therap Adv Gastroenterol 2017; 10: 4253

[9] Johnson G, Webster G, Boskoski I et al. Curriculum for ERCP and endoscopic ultrasound training in Europe: European Society of Gastrointestinal Endoscopy (ESGE) Position Statement. Endoscopy 2021; 53: 1071-1087

[10] Minaga K, Kitano M, Yamashita $Y$ et al. Stent migration into the abdominal cavity after EUS-guided hepaticogastrostomy. Gastrointest Endosc 2017: 85: 263-264

[11] Okuno N, Hara K, Mizuno $\mathrm{N}$ et al. Stent migration into the peritoneal cavity following endoscopic ultrasound-guided hepaticogastrostomy. Endoscopy 2015; 47: (Suppl. 01): E311

[12] Veitch AM, Radaelli F, Alikhan R et al. Endoscopy in patients on antiplatelet or anticoagulant therapy: British Society of Gastroenterology (BSG) and European Society of Gastrointestinal Endoscopy (ESGE) guideline update. Endoscopy 2021; 53: 947-969

[13] Anderloni A, Attili F, Sferrazza A et al. EUS-guided gallbladder drainage using a lumen-apposing self-expandable metal stent in patients with coagulopathy or anticoagulation therapy: a case series. Endosc Int Open 2017; 5: E1100-E1103

[14] Ogura T, Nishioka N, Ueno S et al. Antiplatelet and/or anticoagulant treatment does not increase hemorrhagic adverse events during EUS-guided biliary drainage. Gastrointest Endosc 2020; 92: 659666

[15] Saftoiu A, Ciobanu L, Seicean A et al. Arterial bleeding during EUSguided pseudocyst drainage stopped by placement of a covered self-expandable metal stent. BMC Gastroenterol 2013; 13: 93

[16] Berrios-Torres SI, Umscheid CA, Bratzler DW et al. Centers for Disease Control and Prevention Guideline for the prevention of surgical site infection, 2017. JAMA Surg 2017; 152: 784-791

[17] Moon E, Tam MD, Kikano RN et al. Prophylactic antibiotic guidelines in modern interventional radiology practice. Semin Intervent Radiol 2010: $27: 327-337$
[18] Kamata K, Takenaka M, Minaga K et al. Stent migration during EUSguided hepaticogastrostomy in a patient with massive ascites: Troubleshooting using additional EUS-guided antegrade stenting. Arab J Gastroenterol 2017; 18: 120-121

[19] Chantarojanasiri T, Ratanachu-Ek T, Pausawasdi N. What you need to know before performing endoscopic ultrasound-guided hepaticogastrostomy. Clin Endosc 2021; 54: 301-308

[20] Ogura T, Higuchi K. Technical tips for endoscopic ultrasound-guided hepaticogastrostomy. World J Gastroenterol 2016; 22: 3945-3951

[21] Martinez B, Martinez J, Casellas JA et al. Endoscopic ultrasoundguided rendezvous in benign biliary or pancreatic disorders with a 22-gauge needle and a 0.018-inch guidewire. Endosc Int Open 2019; 7: E1038-E1043

[22] Lakhtakia S, Chavan R, Ramchandani M et al. EUS-guided rendezvous with a steerable access needle in choledocholithiasis. VideoGIE 2020; 5: 359-361

[23] Marrache MK, Al-Sabban A, Itani M et al. Endoscopic ultrasoundguided rendezvous ERCP using a steerable access device. Endoscopy 2020; 52: E355-E356

[24] Prachayakul V, Aswakul P. Feasibility and safety of using Soehendra stent retriever as a new technique for biliary access in endoscopic ultrasound-guided biliary drainage. World J Gastroenterol 2015; 21: 2725-2730

[25] Park DH, Jang JW, Lee SS et al. EUS-guided biliary drainage with transluminal stenting after failed ERCP: predictors of adverse events and long-term results. Gastrointest Endosc 2011; 74: 1276-1284

[26] Vanella G, Bronswijk M, Maleux G et al. EUS-guided intrahepatic biliary drainage: a large retrospective series and subgroup comparison between percutaneous drainage in hilar stenoses or postsurgical anatomy. Endosc Int Open 2020; 8: E1782-E1794

[27] Ichkhanian Y, Yang J, James TW et al. EUS-directed transenteric ERCP in non-Roux-en-Y gastric bypass surgical anatomy patients (with video). Gastrointest Endosc 2020; 91: 1188-1194 e1182

[28] Itoi T, Ishii K, Ikeuchi $\mathrm{N}$ et al. Prospective evaluation of endoscopic ultrasonography-guided double-balloon-occluded gastrojejunostomy bypass (EPASS) for malignant gastric outlet obstruction. Gut 2016; 65: 193-195

[29] Anderloni A, Attili F, Carrara S et al. Intra-channel stent release technique for fluoroless endoscopic ultrasound-guided lumen-apposing metal stent placement: changing the paradigm. Endosc Int Open 2017; 5: E25-E29

[30] Iwashita T, Lee JG, Shinoura S et al. Endoscopic ultrasound-guided rendezvous for biliary access after failed cannulation. Endoscopy 2012; 44: 60-65

[31] Iwashita T, Yasuda I, Mukai T et al. EUS-guided rendezvous for difficult biliary cannulation using a standardized algorithm: a multicenter prospective pilot study (with videos). Gastrointest Endosc 2016; 83: $394-400$

[32] Paik WH, Park DH. Outcomes and limitations: EUS-guided hepaticogastrostomy. Endosc Ultrasound 2019; 8: S44-S49

[33] Yamamoto Y, Ogura T, Nishioka $\mathrm{N}$ et al. Risk factors for adverse events associated with bile leak during EUS-guided hepaticogastrostomy. Endosc Ultrasound 2020; 9: 110-115

[34] Matsumoto K, Kato H, Horiguchi S et al. Efficacy and safety of chemotherapy after endoscopic double stenting for malignant duodenal and biliary obstructions in patients with advanced pancreatic cancer: a single-institution retrospective analysis. BMC Gastroenterol 2018; 18: 157

[35] Amato A, Sinagra E, Celsa C et al. Efficacy and safety of lumen-apposing metal stents or self-expandable metal stents for endoscopic ultrasound-guided choledochoduodenostomy: a systematic review and meta-analysis. Endoscopy 2021; 53: 1037-1047 
[36] Bang JY, Navaneethan U, Hasan M et al. Stent placement by EUS or ERCP for primary biliary decompression in pancreatic cancer: a randomized trial (with videos). Gastrointest Endosc 2018; 88: 9-17

[37] Itonaga M, Kitano M, Hatamaru K et al. Endoscopic ultrasoundguided choledochoduodenostomy using a thin stent delivery system in patients with unresectable malignant distal biliary obstruction: A prospective multicenter study. Dig Endosc 2019; 31: 291-298

[38] de Benito Sanz M, Najera-Munoz R, de la Serna-Higuera C et al. Lumen apposing metal stents versus tubular self-expandable metal stents for endoscopic ultrasound-guided choledochoduodenostomy in malignant biliary obstruction. Surg Endosc 2021; 35: 6754-6762

[39] Matsunami Y, Itoi T, Sofuni A et al. EUS-guided hepaticoenterostomy with using a dedicated plastic stent for the benign pancreaticobiliary diseases: A single-center study of a large case series. Endosc Ultrasound 2021; 10: 294-304

[40] Umeda J, Itoi T, Tsuchiya T et al. A newly designed plastic stent for EUS-guided hepaticogastrostomy: a prospective preliminary feasibility study (with videos). Gastrointest Endosc 2015; 82: 390-396 e392

[41] Kawakami H, Itoi T, Ban T. Intrahepatic biliary stones extraction via an EUS-guided hepaticogastrostomy route confirmed by peroral transluminal video cholangioscopy (with video). J Hepatobiliary Pancreat Sci 2020; 27: E11-E12

[42] Ogura T, Nishioka N, Higuchi K. Transluminal intrahepatic bile duct stone removal using coaxial basket catheter via the previously created EUS-guided hepaticogastrostomy tract (with videos). Endosc Ultrasound 2019; 8: 133-135

[43] Sato T, Nakai Y, Kogure $\mathrm{H}$ et al. Electrohydraulic lithotripsy through a fistula of EUS-guided hepaticogastrostomy: a new approach for right intrahepatic stones. VideoGIE 2019; 4: 420-422

[44] Sportes A, Leblanc S, Bordacahar B et al. Peroral intraductal cholangioscopy-guided laser lithotripsy via endoscopic ultrasound-guided hepaticogastrostomy for intrahepatic bile duct lithiasis. Endoscopy 2019; 51: E135-E136

[45] Okuno N, Hara K, Mizuno N et al. Efficacy of the 6-mm fully covered self-expandable metal stent during endoscopic ultrasound-guided hepaticogastrostomy as a primary biliary drainage for the cases estimated difficult endoscopic retrograde cholangiopancreatography: A prospective clinical study. J Gastroenterol Hepatol 2018; 33: 1413-1421

[46] de Cassan C, Bories E, Pesenti C et al. Use of partially covered and uncovered metallic prosthesis for endoscopic ultrasound-guided hepaticogastrostomy: Results of a retrospective monocentric study. Endosc Ultrasound 2017; 6: 329-335

[47] Ogura T, Yamamoto K, Sano T et al. Stent length is impact factor associated with stent patency in endoscopic ultrasound-guided hepaticogastrostomy. J Gastroenterol Hepatol 2015; 30: 1748-1752

[48] Miyano A, Ogura T, Yamamoto K et al. Clinical impact of the intrascope channel stent release technique in preventing stent migration during EUS-guided hepaticogastrostomy. J Gastrointest Surg 2018; 22: $1312-1318$

[49] Sundaram S, Dhir V. EUS-guided biliary drainage for malignant hilar biliary obstruction: A concise review. Endosc Ultrasound 2021; 10: 154-160

[50] Moryoussef F, Sportes A, Leblanc S et al. Is EUS-guided drainage a suitable alternative technique in case of proximal biliary obstruction? Therap Adv Gastroenterol 2017; 10: 537-544

[51] Ma KW, So H, Cho DH et al. Durability and outcome of endoscopic ultrasound-guided hepaticoduodenostomy using a fully covered metal stent for segregated right intrahepatic duct dilatation. J Gastroenterol Hepatol 2020; 35: 1753-1760
[52] Park S], Choi JH, Park DH et al. Expanding indication: EUS-guided hepaticoduodenostomy for isolated right intrahepatic duct obstruction (with video). Gastrointest Endosc 2013; 78: 374-380

[53] Garcia-Sumalla A, Bazaga S, Gornals JB. EUS-guided biliary rendezvous as an emergent rescue after failed choledochoduodenostomy using a lumen-apposing metal stent. VideoGIE 2021; 6: 263-265

[54] Mangas-Sanjuan C, Bozhychko M, Martinez J et al. Endoscopic management of accidental portal vein puncture during endoscopic ultrasound-guided choledochoduodenostomy. Endoscopy 2020; 52: E47-E48

[55] Martins FP, Rossini LG, Ferrari AP. Migration of a covered metallic stent following endoscopic ultrasound-guided hepaticogastrostomy: fatal complication. Endoscopy 2010; 42: (Suppl. 02): E126E127

[56] Shima $\mathrm{Y}$, Isayama H, Ito $\mathrm{Y}$ et al. Crisscross anchor-stents to prevent metal stent migration during endoscopic ultrasound-guided hepaticogastrostomy. Endoscopy 2014; 46: (Suppl. 01): E563

[57] Wang S, Guo ], Sun S et al. Endoscopic ultrasound-guided repositioning of a migrated metal hepatogastrostomy stent using foreign body forceps. Endoscopy 2016; 48: (Suppl. 01): E28-E29

[58] Sodarat P, Luangsukrerk T, Kongkam P et al. Surgical hepaticogastrostomy as a method for resolving stent migration in endoscopic ultrasound-guided hepaticogastrostomy. Endoscopy 2021; 53: E350-E351

[59] van Geenen EJM, Siersema PD. Stent migration into the abdominal cavity after EUS-guided hepaticogastrostomy. Gastrointest Endosc 2018; 87: 617-618

[60] Manno M, Vavassori S, Deiana S et al. Rescue endoscopic therapy after malfunctioning choledochoduodenostomy in patient with malignant distal biliary obstruction. Endoscopy 2020; 52: E144E145

[61] Mosquera-Klinger G, de la Serna Higuera C, Perez-Miranda M. Endoscopic sump syndrome secondary to EUS-guided choledocho-duodenostomy with a lumen-apposing metal stent. Rev Esp Enferm Dig 2019; 111: 74-76

[62] Zulli C, Dumont JL, Cereatti F et al. Rescue ERCP after delayed migration of a lumen-apposing metal stent following endoscopic ultrasound-guided choledochoduodenostomy. Endoscopy 2020; 52: E215-E216

[63] Attardo S, Auriemma F, Fugazza A et al. Rescue management of recurrent duodenal and biliary obstruction due to lumen-apposing metal stent distal migration and duodenal stent ingrowth. Endoscopy 2019; 51: E118-E119

[64] Garcia-Sumalla A, Loras C, Guarner-Argente C et al. Is a coaxial plastic stent within a lumen-apposing metal stent useful for the management of distal malignant biliary obstruction? Surg Endosc 2021; 35: $4873-4881$

[65] Minaga K, Takenaka M, Okamoto A et al. Reintervention for stent occlusion after endoscopic ultrasound-guided hepaticogastrostomy with novel use of a precut needle-knife. Endoscopy 2018; 50: E153E154

[66] Ogura T, Masuda D, Takeuchi T et al. Simplified reintervention method of EUS-guided hepaticogastrostomy stent obstruction. Gastrointest Endosc 2016; 83: 831

[67] Cahen DL, Gouma DJ, Nio Y et al. Endoscopic versus surgical drainage of the pancreatic duct in chronic pancreatitis. NEJM 2007; 356: 676-684

[68] Krafft MR, Nasr JY. anterograde endoscopic ultrasound-guided pancreatic duct drainage: a technical review. Dig Dis Sci 2019; 64: $1770-1781$

[69] Fujii LL, Topazian MD, Abu Dayyeh BK et al. EUS-guided pancreatic duct intervention: outcomes of a single tertiary-care referral center experience. Gastrointest Endosc 2013; 78: 854-864.e851 
[70] Basiliya K, Veldhuijzen G, Gerges C et al. Endoscopic retrograde pancreatography-guided versus endoscopic ultrasound-guided technique for pancreatic duct cannulation in patients with pancreaticojejunostomy stenosis: a systematic literature review. Endoscopy 2021; 53: 266-276

[71] Francois E, Kahaleh M, Giovannini M et al. EUS-guided pancreaticogastrostomy. Gastrointest Endosc 2002; 56: 128-133

[72] Tyberg A, Sharaiha RZ, Kedia P et al. EUS-guided pancreatic drainage for pancreatic strictures after failed ERCP: a multicenter international collaborative study. Gastrointest Endosc 2017; 85: 164-169

[73] Tessier G, Bories E, Arvanitakis M et al. EUS-guided pancreatogastrostomy and pancreatobulbostomy for the treatment of pain in patients with pancreatic ductal dilatation inaccessible for transpapillary endoscopic therapy. Gastrointest Endosc 2007; 65: 233-241

[74] Krafft MR, Croglio MP, James TW et al. Endoscopic endgame for obstructive pancreatopathy: outcomes of anterograde EUS-guided pancreatic duct drainage. A dual-center study. Gastrointest Endosc 2020; 92: 1055-1066

[75] Chen YI, Levy M], Moreels TG et al. An international multicenter study comparing EUS-guided pancreatic duct drainage with enteroscopy-assisted endoscopic retrograde pancreatography after Whipple surgery. Gastrointest Endosc 2017; 85: 170-177

[76] Kahaleh M, Hernandez AJ, Tokar J et al. EUS-guided pancreaticogastrostomy: analysis of its efficacy to drain inaccessible pancreatic ducts. Gastrointest Endosc 2007; 65: 224-230

[77] Shimamura Y, Mosko J, Teshima C et al. Endoscopic ultrasoundguided pancreatic duct intervention. Clin Endosc 2017; 50: 112-116

[78] Kurihara T, Itoi T, Sofuni A et al. Endoscopic ultrasonography-guided pancreatic duct drainage after failed endoscopic retrograde cholangiopancreatography in patients with malignant and benign pancreatic duct obstructions. Dig Endosc 2013; 25: (Suppl. 02): 109116

[79] Oh D, Park DH, Cho MK et al. Feasibility and safety of a fully covered self-expandable metal stent with antimigration properties for EUSguided pancreatic duct drainage: early and midterm outcomes (with video). Gastrointest Endosc 2016; 83: 366-373 e362

[80] Itoi T, Kasuya K, Sofuni A et al. Endoscopic ultrasonography-guided pancreatic duct access: techniques and literature review of pancreatography, transmural drainage and rendezvous techniques. Dig Endosc 2013; 25: 241-252

[81] Dumonceau JM, Delhaye M, Tringali A et al. Endoscopic treatment of chronic pancreatitis: European Society of Gastrointestinal Endoscopy (ESGE) Guideline - Updated August 2018. Endoscopy 2019; 51 : 179-193

[82] van Huijgevoort NCM, Veld JV, Fockens P et al. Success of extracorporeal shock wave lithotripsy and ERCP in symptomatic pancreatic duct stones: a systematic review and meta-analysis. Endosc Int Open 2020; 8: E1070-E1085

[83] McCarty TR, Hathorn KE, Bazarbashi AN et al. Endoscopic gallbladder drainage for symptomatic gallbladder disease: a cumulative systematic review meta-analysis. Surg Endosc 2021; 35: 4964-4985

[84] Teoh AYB, Kitano M, Itoi T et al. Endosonography-guided gallbladder drainage versus percutaneous cholecystostomy in very high-risk surgical patients with acute cholecystitis: an international randomised multicentre controlled superiority trial (DRAC 1). Gut 2020; 69: 1085-1091

[85] Teoh AYB, Leung CH, Tam PTH et al. EUS-guided gallbladder drainage versus laparoscopic cholecystectomy for acute cholecystitis: a propensity score analysis with 1-year follow-up data. Gastrointest Endosc 2021; 93: 577-583

[86] Krishnamoorthi R, Jayaraj M, Thoguluva Chandrasekar V et al. EUSguided versus endoscopic transpapillary gallbladder drainage in high-risk surgical patients with acute cholecystitis: a systematic review and meta-analysis. Surg Endosc 2020; 34: 1904-1913
[87] Ahmed O, Rogers AC, Bolger JC et al. Meta-analysis of outcomes of endoscopic ultrasound-guided gallbladder drainage versus percutaneous cholecystostomy for the management of acute cholecystitis. Surg Endosc 2018; 32: 1627-1635

[88] Anderloni A, Buda A, Vieceli F et al. Endoscopic ultrasound-guided transmural stenting for gallbladder drainage in high-risk patients with acute cholecystitis: a systematic review and pooled analysis. Surg Endosc 2016; 30: 5200-5208

[89] Podboy A, Yuan J, Stave CD et al. Comparison of EUS-guided endoscopic transpapillary and percutaneous gallbladder drainage for acute cholecystitis: a systematic review with network meta-analysis. Gastrointest Endosc 2021; 93: 797-804 e791

[90] Imai H, Kitano M, Omoto S et al. EUS-guided gallbladder drainage for rescue treatment of malignant distal biliary obstruction after unsuccessful ERCP. Gastrointest Endosc 2016; 84: 147-151

[91] Chang JI, Dong E, Kwok KK. Endoscopic ultrasound-guided transmural gallbladder drainage in malignant obstruction using a novel lumen-apposing stent: a case series (with video). Endosc Int Open 2019; 7: E655-E661

[92] Teoh AYB. Outcomes and limitations in EUS-guided gallbladder drainage. Endosc Ultrasound 2019; 8: S40-S43

[93] Law R, Grimm IS, Stavas JM et al. Conversion of percutaneous cholecystostomy to internal transmural gallbladder drainage using an endoscopic ultrasound-guided, lumen-apposing metal stent. Clin Gastroenterol Hepatol 2016; 14: 476-480

[94] Saumoy M, Novikov A, Kahaleh M. Long-term outcomes after EUSguided gallbladder drainage. Endosc Ultrasound 2018; 7: 97-101

[95] Issa D, Irani S, Law R et al. Endoscopic ultrasound-guided gallbladder drainage as a rescue therapy for unresectable malignant biliary obstruction: a multicenter experience. Endoscopy 2021; 53: 827-831

[96] Chan SM, Teoh AYB, Yip HC et al. Feasibility of per-oral cholecystoscopy and advanced gallbladder interventions after EUS-guided gallbladder stenting (with video). Gastrointest Endosc 2017; 85: 1225-1232

[97] Teoh AY, Perez-Miranda M, Kunda R et al. Outcomes of an international multicenter registry on EUS-guided gallbladder drainage in patients at high risk for cholecystectomy. Endosc Int Open 2019; 7: E964-E973

[98] Cho SH, Oh D, Song T] et al. Comparison of the effectiveness and safety of lumen-apposing metal stents and anti-migrating tubular self-expandable metal stents for EUS-guided gallbladder drainage in high surgical risk patients with acute cholecystitis. Gastrointest Endosc 2020; 91: 543-550

[99] James TW, Krafft M, Croglio M et al. EUS-guided gallbladder drainage in patients with cirrhosis: results of a multicenter retrospective study. Endosc Int Open 2019; 7: E1099-E1104

[100] Dollhopf M, Larghi A, Will U et al. EUS-guided gallbladder drainage in patients with acute cholecystitis and high surgical risk using an electrocautery-enhanced lumen-apposing metal stent device. Gastrointest Endosc 2017; 86: 636-643

[101] Teoh AY, Binmoeller KF, Lau JY. Single-step EUS-guided puncture and delivery of a lumen-apposing stent for gallbladder drainage using a novel cautery-tipped stent delivery system. Gastrointest Endosc 2014; 80: 1171

[102] Perez-Miranda M. Technical considerations in EUS-guided gallbladder drainage. Endosc Ultrasound 2018; 7: 79-82

[103] Teoh AYB, Serna C, Penas I et al. Endoscopic ultrasound-guided gallbladder drainage reduces adverse events compared with percutaneous cholecystostomy in patients who are unfit for cholecystectomy. Endoscopy 2017; 49: 130-138

[104] Ge N, Sun S, Wang S et al. Endoscopic ultrasound-assisted transmural cholecystoduodenostomy or cholecystogastrostomy as a bridge for per-oral cholecystoscopy therapy using double-flanged fully covered metal stent. BMC Gastroenterol 2016; 16: 9 
[105] Higa JT, Sahar N, Kozarek RA et al. EUS-guided gallbladder drainage with a lumen-apposing metal stent versus endoscopic transpapillary gallbladder drainage for the treatment of acute cholecystitis (with videos). Gastrointest Endosc 2019; 90: 483-492

[106] Kamata K, Takenaka M, Kitano M et al. Endoscopic ultrasound-guided gallbladder drainage for acute cholecystitis: Long-term outcomes after removal of a self-expandable metal stent. World J Gastroenterol 2017; 23: 661-667

[107] Choi JH, Lee SS, Park DH et al. Long-term outcomes after endoscopic ultrasonography-guided gallbladder drainage for acute cholecystitis. Endoscopy 2014; 46: 656-661

[108] Irani S, Baron TH, Grimm IS et al. EUS-guided gallbladder drainage with a lumen-apposing metal stent (with video). Gastrointest Endosc 2015; 82: 1110-1115

[109] Song T], Park DH, Eum JB et al. EUS-guided cholecystoenterostomy with single-step placement of a $7 \mathrm{~F}$ double-pigtail plastic stent in patients who are unsuitable for cholecystectomy: a pilot study (with video). Gastrointest Endosc 2010; 71: 634-640

[110] Jang JW, Lee SS, Song T] et al. Endoscopic ultrasound-guided transmural and percutaneous transhepatic gallbladder drainage are comparable for acute cholecystitis. Gastroenterology 2012; 142: 805-811

[111] Ichkhanian Y, Vosoughi K, Aghaie Meybodi M et al. Comprehensive analysis of adverse events associated with gastric peroral endoscopic myotomy: an international multicenter study. Surg Endosc 2021; 35: 1755-1764

[112] Bronswijk M, Vanella G, van Malenstein $\mathrm{H}$ et al. Laparoscopic versus EUS-guided gastroenterostomy for gastric outlet obstruction: an international multicenter propensity score-matched comparison (with video). Gastrointest Endosc 2021; 94: 526-536.e2

[113] Khashab MA, Bukhari M, Baron TH et al. International multicenter comparative trial of endoscopic ultrasonography-guided gastroenterostomy versus surgical gastrojejunostomy for the treatment of malignant gastric outlet obstruction. Endosc Int Open 2017; 5: E275-E281

[114] Bronswijk M, van Malenstein H, Laleman W et al. EUS-guided gastroenterostomy: Less is more! The wireless EUS-guided gastroenterostomy simplified technique VideoGIE 2020; 5: 442

[115] Itoi T, Baron TH, Khashab MA et al. Technical review of endoscopic ultrasonography-guided gastroenterostomy in 2017. Dig Endosc 2017; 29: 495-502

[116] Marrache MK, Itani MI, Farha J et al. Endoscopic gastrointestinal anastomosis: a review of established techniques. Gastrointest Endosc 2021; 93: 34-46

[117] Tonozuka R, Tsuchiya T, Mukai S et al. Endoscopic ultrasonographyguided gastroenterostomy techniques for treatment of malignant gastric outlet obstruction. Clin Endosc 2020; 53: 510-518

[118] Attam R, Leslie D, Freeman M et al. EUS-assisted, fluoroscopically guided gastrostomy tube placement in patients with Roux-en-Y gastric bypass: a novel technique for access to the gastric remnant. Gastrointest Endosc 2011; 74: 677-682

[119] Attam R, Leslie D, Arain MA et al. EUS-guided sutured gastropexy for transgastric ERCP (ESTER) in patients with Roux-en-Y gastric bypass: a novel, single-session, minimally invasive approach. Endoscopy 2015; 47: 646-649

[120] Kedia P, Kumta NA, Widmer J et al. Endoscopic ultrasound-directed transgastric ERCP (EDGE) for Roux-en-Y anatomy: a novel technique. Endoscopy 2015; 47: 159-163

[121] Kedia P, Tarnasky PR, Nieto J et al. EUS-directed transgastric ERCP (EDGE) versus laparoscopy-assisted ERCP (LA-ERCP) for Roux-en-Y gastric bypass (RYGB) anatomy: a multicenter early comparative experience of clinical outcomes. J Clin Gastroenterol 2019; 53: 304308
[122] Kochhar GS, Mohy-Ud-Din N, Grover A et al. EUS-directed transgastric endoscopic retrograde cholangiopancreatography versus laparoscopic-assisted ERCP versus deep enteroscopy-assisted ERCP for patients with RYGB. Endosc Int Open 2020; 8: E877-E882

[123] Krafft MR, Fang W, Nasr JY. Shortened-interval dual-session EDGE reduces the risk of LAMS dislodgement while facilitating timely ERCP. Dig Dis Sci 2021; 66: 2776-2785

[124] Tyberg A, Kedia P, Tawadros A et al. EUS-directed transgastric endoscopic retrograde cholangiopancreatography (EDGE): the first learning curve. J Clin Gastroenterol 2020; 54: 569-572

[125] Runge TM, Chiang AL, Kowalski TE et al. Endoscopic ultrasound-directed transgastric ERCP (EDGE): a retrospective multicenter study. Endoscopy 2021; 53: 611-618

[126] Prakash S, Elmunzer BJ, Forster EM et al. Endoscopic ultrasound-directed transgastric ERCP (EDGE): a systematic review describing the outcomes, adverse events, and knowledge gaps. Endoscopy 2022; 54: $52-61$

[127] Shinn B, Boortalary T, Raijman I et al. Maximizing success in singlesession EUS-directed transgastric ERCP: a retrospective cohort study to identify predictive factors of stent migration. Gastrointest Endosc 2021; 94: 727-732

[128] Keane MG, Higa JT, La Selva D et al. Suturing LAMS allows for samesession EUS-directed transgastric intervention (EGDI) in patients with RYGB anatomy: a multicenter study. Gastrointestinal Endoscopy 2021; 93: AB208

[129] Wang T], Thompson CC, Ryou M. Gastric access temporary for endoscopy (GATE): a proposed algorithm for EUS-directed transgastric ERCP in gastric bypass patients. Surg Endosc 2019; 33: 20242033

[130] James TW, Baron TH. Endoscopic ultrasound-directed transgastric ERCP (EDGE): a single-center US experience with follow-up data on fistula closure. Obes Surg 2019; 29: 451-456

[131] Chavan R, Ramchandani M, Nabi Z et al. Luminal and extraluminal bleeding during EUS-guided double-balloon-occluded gastrojejunostomy bypass in benign gastric outlet obstruction with portal hypertension. VideoGIE 2020; 5: 64-67

[132] Hu J, Wang G, Zhang K et al. Retrieval anchor-assisted endoscopic ultrasound-guided gastroenterostomy for gastric outlet obstruction. Scand J Gastroenterol 2020; 55: 865-868

[133] Irani S. Placing a lumen-apposing metal stent despite ascites: feasibility and safety. VideoGIE 2020; 5: 586-590

[134] Irani S, Khashab M. Gastric outlet obstruction: when you cannot do an endoscopic gastroenterostomy or enteral stent, try an endoscopic duodenojejunostomy or jejunojejunostomy. VideoGIE 2020; 5: $125-128$

[135] Khashab MA, Giovannini M. How I do therapeutic EUS. Endoscopy 2019; 51: 772-774

[136] Khashab MA, Kumbhari V, Grimm IS et al. EUS-guided gastroenterostomy: the first U.S. clinical experience (with video). Gastrointest Endosc 2015; 82: 932-938

[137] Khashab MA, Tieu AH, Azola A et al. EUS-guided gastrojejunostomy for management of complete gastric outlet obstruction. Gastrointest Endosc 2015; 82: 745

[138] Ghandour B, Bejjani M, Irani SS et al. Classification, outcomes, and management of misdeployed stents during EUS-guided gastroenterostomy. Gastrointest Endosc 2022; 95: 80-89

[139] Chen YI, Itoi T, Baron TH et al. EUS-guided gastroenterostomy is comparable to enteral stenting with fewer re-interventions in malignant gastric outlet obstruction. Surg Endosc 2017; 31: 29462952

[140] Chen YI, Kunda R, Storm AC et al. EUS-guided gastroenterostomy: a multicenter study comparing the direct and balloon-assisted techniques. Gastrointest Endosc 2018; 87: 1215-1221 
[141] Kastelijn JB, Moons LMG, Garcia-Alonso FJ et al. Patency of endoscopic ultrasound-guided gastroenterostomy in the treatment of malignant gastric outlet obstruction. Endosc Int Open 2020; 8: E1194-E1201

[142] Bukhari M, Kowalski T, Nieto J et al. An international, multicenter, comparative trial of EUS-guided gastrogastrostomy-assisted ERCP versus enteroscopy-assisted ERCP in patients with Roux-en-Y gastric bypass anatomy. Gastrointest Endosc 2018; 88: 486-494

[143] Kedia P, Sharaiha RZ, Kumta NA et al. Internal EUS-directed transgastric ERCP (EDGE): game over. Gastroenterology 2014; 147: 566568

[144] Kedia P, Tyberg A, Kumta NA et al. EUS-directed transgastric ERCP for Roux-en-Y gastric bypass anatomy: a minimally invasive approach. Gastrointest Endosc 2015; 82: 560-565

[145] Crismale JF, Riff BP, Schwartz M et al. Closure of an iatrogenic gastrogastric fistula created during EUS-directed transgastric ERCP. VideoGIE 2016; 1: 61-62

[146] Duloy A, Hammad H, Shah RJ. An adverse event of EUS-directed transgastric ERCP: stent-in-stent technique to bridge the peritoneal gap. VideoGIE 2019; 4: 508-511

[147] Irani S, Yang J, Khashab MA. Mitigating lumen-apposing metal stent dislodgment and allowing safe, single-stage EUS-directed transgastric ERCP. VideoGIE 2018; 3: 322-324

[148] Barthet M, Binmoeller KF, Vanbiervliet G et al. Natural orifice transluminal endoscopic surgery gastroenterostomy with a biflanged lumen-apposing stent: first clinical experience (with videos). Gastrointest Endosc 2015; 81: 215-218
[149] James TW, Greenberg S, Grimm IS et al. EUS-guided gastroenteric anastomosis as a bridge to definitive treatment in benign gastric outlet obstruction. Gastrointest Endosc 2020; 91: 537-542

[150] Ge PS, Young JY, Dong W et al. EUS-guided gastroenterostomy versus enteral stent placement for palliation of malignant gastric outlet obstruction. Surg Endosc 2019; 33: 3404-3411

[151] Ichkhanian $Y$, Runge $T$, Jovani M et al. Management of adverse events of EUS-directed transgastric ERCP procedure. VideoGIE 2020; 5: $260-263$

[152] Iqbal U, Khara HS, Hu Y et al. EUS-guided gastroenterostomy for the management of gastric outlet obstruction: A systematic review and meta-analysis. Endosc Ultrasound 2020; 9: 16-23

[153] McCarty TR, Garg R, Thompson CC et al. Efficacy and safety of EUSguided gastroenterostomy for benign and malignant gastric outlet obstruction: a systematic review and meta-analysis. Endosc Int Open 2019; 7: E1474-E1482

[154] Amin S, Sethi A. Endoscopic ultrasound-guided gastrojejunostomy. Gastrointest Endosc Clin N Am 2017; 27: 707-713

[155] Chen YI, James TW, Agarwal A et al. EUS-guided gastroenterostomy in management of benign gastric outlet obstruction. Endosc Int Open 2018; 6: E363-E368

[156] Hassan C, Ponchon T, Bisschops R et al. European Society of Gastrointestinal Endoscopy (ESGE) Publications Policy - Update 2020. Endoscopy 2020; 52: 123-126 